NBER WORKING PAPER SERIES

\title{
WITHIN-JOB WAGE INEQUALITY: PERFORMANCE PAY AND JOB RELATEDNESS
}

\author{
Rongsheng Tang \\ Yang Tang \\ Ping Wang \\ Working Paper 27390 \\ http://www.nber.org/papers/w27390 \\ NATIONAL BUREAU OF ECONOMIC RESEARCH \\ 1050 Massachusetts Avenue \\ Cambridge, MA 02138 \\ June 2020
}

We thank Daniel Parent, Carl Sanders and David Wiczer for sharing their codes and Gaetano Antinolfi, Michele Boldrin, Fatih Guvenen, Tim Lee, Rodolfo Manuelli, B. Ravikumar, Raul Santaeulalia-Llopis, Yongseok Shin, Guillaume Vandenbroucke, David Wiczer for helpful comments. We have also benefited from comments by participants at the Asian Meeting of the Econometric Society, China Meeting of Econometric Society, Midwest Macroeconomics Meeting, North American Meeting of Econometric Society, QMUL-SUFE Workshop in Economics, and Taipei International Conference on Growth, Trade and Dynamics. Rongsheng Tang is grateful for the financial support from the National Natural Science Foundation of China (Grant No.71803112). The views expressed herein are those of the authors and do not necessarily reflect the views of the National Bureau of Economic Research.

NBER working papers are circulated for discussion and comment purposes. They have not been peer-reviewed or been subject to the review by the NBER Board of Directors that accompanies official NBER publications.

(C) 2020 by Rongsheng Tang, Yang Tang, and Ping Wang. All rights reserved. Short sections of text, not to exceed two paragraphs, may be quoted without explicit permission provided that full credit, including $\odot$ notice, is given to the source. 
Within-Job Wage Inequality: Performance Pay and Job Relatedness

Rongsheng Tang, Yang Tang, and Ping Wang

NBER Working Paper No. 27390

June 2020

JEL No. E24,I24,J31

\begin{abstract}
Over the past few decades, we find that about $80 \%$ of the widening residual wage inequality to be within jobs. We propose performance-pay incidence and job relatedness as two primary factors driving within-job inequality and embed them into a sorting equilibrium framework. We show that equilibrium sorting is positive assortative both within-job and across jobs. While performance-pay position amplifies within-job wage inequality through self-selection, the overall relationship between job relatedness and within-job wage inequality is found generally ambiguous. To quantify the role played by these factors, we calibrate the model to the US economy in 2000, where the model can account around 92\%of the changes in within-job inequality among the highly educated from 1990 to 2000. Counterfactual analysis shows the contributions of performance-pay incidence and job relatedness are about 42\%and 26\%, respectively, both higher than that of job-specific productivity. While performance-pay incidence is particularly crucial for within-job wage dispersion in business/professional industry and professional occupation, job relatedness is the most important for mining/goods/construction industry and sales occupation.
\end{abstract}

Rongsheng Tang

Institute for Advanced Research

Shanghai University of Finance and Economics

Shanghai

China

tang.rongsheng@sufe.edu.cn

Yang Tang

Department of Economics

Nanyang Technological University

50 Nanyang Avenue, Singapore 639798

tangyang@ntu.edu.sg
Ping Wang

Department of Economics

Washington University in St. Louis

Campus Box 1208

One Brookings Drive

St. Louis, MO 63130-4899

and NBER

pingwang@wustl.edu 


\section{Introduction}

It has been extensively documented in the literature that residual wage inequality accounts for a major proportion of the overall wage inequality and residual wage inequality tends to increase faster over time among individuals with higher education. In this paper, we go beyond by showing that four-fifths of residual wage inequality have been driven by wage dispersion within jobs, defined by industry-occupation pairs. Understanding the causes of within-job inequality is thus crucial for us to understand the main sources of the overall inequality. We propose performance-pay incidence and job relatedness as the two important channels.

We classify individuals into the high and low education groups according to their years of schooling. We then compute residual wage inequality for both groups during 1983-2013. The results suggest inequality within the high education group not only appears to be higher but also increases faster than the low education group - the pattern becomes more prominent in the 1990s and the 2000s. In the high education group, even if we control for more job characteristics including industry, occupation, firm size, location, citizenship etc., about $90 \%$ of residual wage inequality still remains. ${ }^{1}$ This implies that wage inequality is primarily driven by within-industry/occupation inequality. To further confirm this finding, we decompose residual wage inequality into between-job and within-job components over all industry-occupation pairs. The decomposition result shows that within-job inequality accounts for more than $80 \%$ of residual wage inequality between 1983 and 2013, and its contribution to the change ranges from $70 \%$ to $110 \%$ between 1990 and $2002 .^{2}$ To the best of our knowledge, this pattern has not been explored in the literature.

In order to explain the aforementioned facts, we propose performance-pay incidence and job relatedness as the two potential causes of within-job inequality, in addition to differential job productivities. Workers in performance-pay position are paid according to how much they contribute, and such payments usually include bonus, commission, piece-rate and tips. The counter-part to this is the payment of a fixed hourly wage. While the literature has identified

\footnotetext{
${ }^{1}$ More details can be found in section 2.2.

${ }^{2}$ See more details in section 2.3.
} 
a positive wage effect of performance-pay, ${ }^{3}$ we further examine the relationship between within-job wage inequality and performance-pay incidence. We find a significant positive relationship: jobs with higher performance-pay incidence usually have higher wage inequality. This hints the importance of the rising performance-pay incidence for the widening wage dispersion as observed.

With regard to job relatedness, we measure it as the relatedness between the field of study of the highest degree earned and the occupation at the current job. ${ }^{4}$ We show that job relatedness has positive wage effect: among workers with similar schooling levels, those whose majors are more related to their jobs usually receive higher compensation than others. Moreover, we find a negative relationship between job relatedness and within-job wage inequality: jobs with more related matches are paid more equally. This implies that a reduction in job relatedness as observed in data could also serve to explain within-job wage inequality.

The empirical analysis have only established simple correlation between performance-pay incidence or job relatedness and within-job inequality. However, in the reality, job relatedness may in turn affect performance-pay incidence, and within-job inequality may also influence the magnitude of job relatedness and performance-pay incidence. This thereby requires a model to discipline the interactions between them. In this paper, we embed both channels into a sorting equilibrium framework and quantify their importance in driving within-job wage inequality among highly educated workers. Workers are heterogeneous in their innate abilities, whereas jobs differ in their productivities. Each job is associated with different productivities and contains two positions with different payment schemes: performance-pay and fixed-pay. In the fixed-pay position, a worker earns a pooled wage which is independent of worker and job characteristics. In performance-pay position, a worker's pay positively depends on his contribution to production. Job relatedness is modeled as the probability that the worker finds the job related to his major. The worker at a related job gets to draw an idiosyncratic productivity premium, which leads to higher wage payment compared with

\footnotetext{
${ }^{3}$ See, for example, Lemieux, MacLeod and Parent (2009).

${ }^{4}$ The terminology varies from skill mismatch, education mismatch, overeducation, overemployment and so on, see Leuven and Oosterbeek (2011) for a survey.
} 
an identical worker at an unrelated job.

Job-specific disutilities are incurred for workers in performance-pay position. This is to capture the monitoring cost to prevent workers from shirking. Job relatedness and the resulting productivity premium also vary by jobs. In sorting equilibrium, workers optimally choose over jobs and positions. Under proper assumptions, we show that equilibrium sorting is positive assortative, with the least talented workers choosing fixed-pay position and the more talented workers selecting performance-pay position at different jobs based on job productivities and the random draw of productivity premium induced by job relatedness.

Within-job wage inequality can be decomposed into the wage inequality within performancepay position and the differences in the average wage between performance-pay and fixed-pay positions. Analytically we can establish a positive relationship between performance-pay incidence and within-job inequality. We are also able to prove that, given sorting, the wage inequality within performance-pay position increases with job relatedness, but the overall relationship between job relatedness and within-job wage inequality is generally ambiguous.

To quantify the importance of performance-pay incidence and job relatedness for the rising wage inequality, we calibrate the model by matching several key job-specific features on wage inequality and employment of the US economy in 2000. The overall fitness of the calibrated model is decent. To further disentangle how performance-pay, job relatedness, job-specific productivities and sorting affect the pattern of within-job inequality, we conduct a counterfactual based decomposition exercise. This is done by changing the value of each job-specific series in 2000 into their correspondent values in 1990, while maintaining all other parameters at their benchmark value.

The quantitative results show that our model can account around $92 \%$ of the changes in within-job wage inequality among the highly educated from 1990 to 2000. While the rising performance-pay incidence explains $42 \%$ of the widening wage inequality, the reduction in job relatedness contributes to $26 \%$ of such changes. Thus, the two primary factors proposed together account for over two-thirds of observed changes in wage dispersion, while job-specific productivity only accounts for about a quarter of such changes.

By performing additional decomposition analysis by different grouping, we find the contribution of each channel vary greatly across jobs. Specifically, performance-pay inci- 
dence is found particularly crucial for within-job wage dispersion in business/professional industry and professional occupation. Job relatedness is the most important for mining/goods/construction industry and sales occupation. The conventional factor - job-specific productivity - is found more essential for wage dispersion in personal service/trade industry and sales/clerical/operative labor occupation.

We further look into grouping by changes in ranking of job earnings and employment shares. We find performance-pay incidence playing the greatest role in jobs with stable ranking, job relatedness most crucial for jobs dropped in ranking, whereas job-specific productivity most important for jobs rising in ranking. Finally, for the rise in wage inequality in individual jobs, performance-pay incidence contributes greatly to such change in the businessprofessional pair, job relatedness crucially in the transportation-sales pair and job-specific productivity in the goods-clerical pair.

Our findings suggest that any policies aiming at reducing the wage inequality should focus more on the source of the wage dispersions within jobs. While the rising provision of performance-pay jobs and the widening job-specific productivity are natural causes of inequality that need not require policy intervention, the dispersion stemming from reduction in the relatedness between the college major and the job may deserve more policy attention.

\section{Related Literature}

A large number of studies document the trend of wage inequality that has generally been increasing since the 1970s. (e.g. Katz and Autor (1999), Card and DiNardo (2002), Piketty and Saez (2003), Autor, Katz and Kearney (2008), Acemoglu and Autor (2011), Piketty and Saez (2014), Beaudry, Green and Sand (2014), Lee, Shin and Lee (2015)). One classical theory on explaining increase of wage inequality is the change of skill premium due to skill biased technology change (SBTC). (e.g. Juhn, Murphy and Pierce (1993), Krusell et al. (2000), Galor and Moav (2000), Shi (2002), Acemoglu (2003), Beaudry and Green (2005). Literature on the high education group suggests that it is fruitful to study wage inequality within education group (e.g. Altonji, Kahn and Speer (2014)). Altonji, Kahn and Speer (2016) argue that earning difference across college majors can be larger than the skill premium between college and the high school. 
Recent literature focuses on the decomposition of wage inequality. Barth et al. (2011) emphasize the role of plant difference within industry and argue that this could explain $2 / 3$ of the wage inequality in the US. Card, Heining and Kline (2013) show that plant heterogeneity and assortativeness between plants and worker explains a large part of the increase of wage inequality in West Germany. Mueller, Ouimet and Simintzi (2017) study the skill premium within firms, and find that firm growth has contributed to the increase of wage inequality. Papageorgiou (2010) highlights the labor markets within firms and concludes that the within firm part might explain $12.5 \%$ to $1 / 3$ of the rise in wage inequality. Song et al. (2018), however, argue that the between-firm component is more important.

There is also a number of literature founded on the decomposition across occupations. While Kambourov and Manovskii (2009) argue that the variability of productivity shocks on occupations coupled with endogenous occupational mobility could account for most of the increase in within-group wage inequality between the 1970s and middle 1990s, Scotese (2012) shows that changes in wage dispersion within occupation are quantitatively as important as wage change between occupations for explaining wage inequality between 1980 and 2000 .

Performance-pay Some literature on performance-pay studies incentives and productivity. (e.g. Jensen and Murphy (1990), Lazear (2000)). Other literature explains the WhiteBlack wage gap through the difference of tendency on performance pay across races (Heywood and Parent (2012)). The most relevant paper to our study is Lemieux, MacLeod and Parent (2009). In their paper, the authors suggest performance-pay as a channel through which the underlying changes in return to skill get translated into higher wage inequality. Their results show that $21 \%$ of the growth in the variance of wage can be explained between the late 1970s and the early 1990s. Performance-pay position tends to be concentrated in the upper end of the wage distribution; for this reason, it provides a potential channel to study within-group inequality.

Job relatedness The general idea of job relatedness is that people with the same characteristics might have different productivity from the job or machine they are working on. Violante (2002) provides a channel through vintage capital to decompose residual wage 
inequality into worker's ability dispersion, machine's productivity dispersion and the correlation of these two. The author argues that this channel could explain most transitory wage inequality and $30 \%$ of residual wage inequality. Jovanovic (2014) builds a model of learning by doing to emphasize the role of match between employees and employers; under this framework he discusses the role of improving signal quality and assignment efficiency.

In terms of measurement, there are generally two approaches in the literature. The first one is to measure the distance between skill requirement and acquirement based on scores of skills from NLSY79 and O*NET (e.g. Sanders (2014), Guvenen et al. (2020), Lise and Postel-Vinay (2015)). The second approach is to measure job relatedness between field of study in the highest degree and current occupation from data in NSCG (e.g. Robst (2007), Arcidiacono (2004), Ritter and West (2014), Kirkeboen, Leuven and Mogstad (2016)).

Organization of the paper The paper is organized as follows: Section 2 describes the data source and several stylized facts; Section 3 develops a model with performance-pay incidence and job relatedness; Section 4 presents the equilibrium concept and some theoretical results; Section 5 provides quantitative analysis and discusses an extension with multiple dimensions of ability. Section 6 offers the conclusion.

\section{Stylized Facts}

In this section, we document several stylized facts on wage inequality, and its relation with performance-pay position and job relatedness. We first compute wage inequality using different measurements, and decompose it into the between-job and within-job components. We then examine the relationship between performance-pay incidence and within-job wage inequality. Finally, we document the wage effect of job relatedness, and its relationship with within-job wage inequality. 


\subsection{Data}

Data in this paper are collected from several sources: the March Current Population Survey (March CPS), ${ }^{5}$ Panel Study of Income Dynamics (PSID), National Survey of College Graduates (NSCG). The March CPS includes the longest high frequency data series enumerating labor force participation and earnings in the US economy. PSID contains detailed information on earnings including commission, bonus, piece-rate and tips. NSCG has information on relatedness between workers' fields of study and current occupations.

CPS In the March CPS, the education level is grouped into six categories: primary, high school dropout, high school graduate, some college, college graduate and post college. The implied schooling years are 6, 9, 12, 14, 16, 18, respectively. The potential experience is then computed according to the difference between the year after graduation and the age. ${ }^{6}$ The highly educated includes workers who have college degree and above, and the proportion of this group increased from $17 \%$ in 1983 to $34 \%$ in $2013 .^{7}$ Center for Economic and Policy Research(CEPR) provides 2-digit and 3-digit occupation and industry code, but the classification are not consistent during 1983-2013. To solve the issue, we build a consistent 1-digit industry and occupation code following the approach in Lemieux, MacLeod and Parent (2009). A consistent 3-digit code is also built following the way proposed by Dorn (2009). The same method is also used to group a consistent 2-digit code. ${ }^{8}$

Only full time and full year workers, defined as those work at least 40 weeks in a year and 35 hours in a week, with age between 16 and 65 are kept in our sample. The wage is defined to be the real hourly earnings, and we drop the earnings which are less than half of minimal wage in 1982 dollar or higher than 1000. In some literature, this top value is pretty low. For example, in Lemieux, MacLeod and Parent (2009) it is 100 (in 1979 dollar), and in Acemoglu and Autor (2011) it is around 180. Since we only focus on the highly educated individuals, we have managed to keep as many observations as possible.

\footnotetext{
${ }^{5}$ The data is collected from Center for Economic and Policy Research(CEPR).

${ }^{6}$ Specifically, the formula to compute the years of experience is given as $\max ($ age - schooling $-6,0)$.

${ }^{7}$ An alternative way is to include people with some college, the reason we don't use it is that the job match data in NSCG only has information on college graduated.

${ }^{8}$ The original 2-digit code is consistent in the following two sub-periods: 1983-2002 and 2003-2013.
} 
PSID The dataset of PSID has been intensively discussed in the literature. We follow Lemieux, MacLeod and Parent (2009) and use the data in this paper to estimate performancepay incidence for the year 1990 and 2000. Performance-pay includes bonus, commission, piece-rate and overtime payment. A major challenge is to identify workers who are in performance-pay position. PSID reports the format of the payment that a worker has received in a given year, such as bonuses, commissions, or piece rates. However, for workers without those payments, we cannot distinguish whether it is because they work in a fixed-pay position or they do not merit a bonus in the given period. Fortunately, the longitudinal nature of the PSID data enables us to track the payment history to examine whether a worker has ever received any form of performance-pay at his current job, which provides a much more accurate measure (see Lemieux, MacLeod and Parent (2009)). The dataset covers year from 1976 to 1999. In order to estimate performance-pay incidence for the year 1990 and 2000, we restrict the data up to 1990 and 1999 in this data set, respectively .

NSCG Every ten years, NSCG provides information on the relatedness between the field of study from the highest degree and the current occupation. It asks people who claimed to have a college degree in the census survey how close the current occupation is related to their fields of study. The three possible responses in the survey include: close, some close and not at all. We take these three responses as the proxy of job relatedness. In particular, the job relatedness is computed as the fraction of people who reported "close" in the survey. The calculation is weighted by the sample weight.

In addition, we have also regrouped the four types of schooling levels in the dataset-16, 18, 19 and 21-into three types: Bachelor (16), Maser (18,19) and PhD (21). The potential experience or tenure is calculated in the same way as in the March CPS dataset. The major code is regrouped as in Altonji, Kahn and Speer (2014). Occupation code is regrouped to be consistent with that in the March CPS. We keep only the full time workers with the age between 16 and 65 and drop those with annual earnings higher than 4 million or less than 2800 USD.

Table A.3 and A.4 present some summary statistics for the year 1990 and 2000, respectively. In the sample, the total observation are 94,360 in 1990 and 55,465 in 2000. The 
average tenure are 19.11 and 20.92, and the annual earnings are 67514.19 and 78042.82 under current year price, respectively. The overall inequality calculated by the variance of $\log$ annual earning has increased from 1990 to 2000.

Job relatedness has not changed very much, and it is around 0.6 in both years. As shown

in Table A.5, job relatedness does not vary much over gender or race groups. However, there is an increasing trend in the education level. In particular, job relatedness is 0.5 among individuals with Bachelor degree, 0.88 among individuals with Ph.D. degree. The trend is similar in 2000. More importantly, job relatedness also vary greatly over occupations, in addition, the relatedness has increased at certain occupations, but decreased at others.

\subsection{Wage inequality}

In this subsection, we compute the wage inequality using the March CPS dataset. We measure the wage inequality as the variance of log hourly earnings. The upper panel of Figure 1 documents the evolution of wage inequality by education group from 1983 to 2013. In general, the wage inequality has been increasing since the 1980s among all the groups. However, the patterns also vary over education groups. Compared with low education group, the highly educated group has a higher level of wage inequality, meanwhile it also increases at a faster speed especially since the late 1990s.

Following the convention in the literature (e.g. Kambourov and Manovskii (2009)), we compute residual wage as the residual from the following regression:

$$
\ln \left(\text { wage }_{i t}\right)=\beta * X_{i t}+\epsilon_{i t}
$$

where $\ln \left(\right.$ wage $\left._{i t}\right)$ is log hourly earnings. $X_{i t}$ controls gender, race, experience and education. Residual wage inequality is then computed as the variance of the residuals. As shown in the lower panel of Figure 1, residual wage inequality takes up a large proportion of the overall wage inequality. The two series also evolve in a similar pattern over time. As a robustness check, we calculate the Gini coefficient and 90/10 ratio as well. Figure A.1 shows that the Gini coefficient has similar pattern as the variance of residuals. For 90-10 ratio, the pattern for high education group still remains similar. In sum, both facts confirm a high within-group 
inequality. In addition, residual wage inequality within the group of the highly educated is higher than the overall average, and it also increased faster especially between 1990 and 2000.

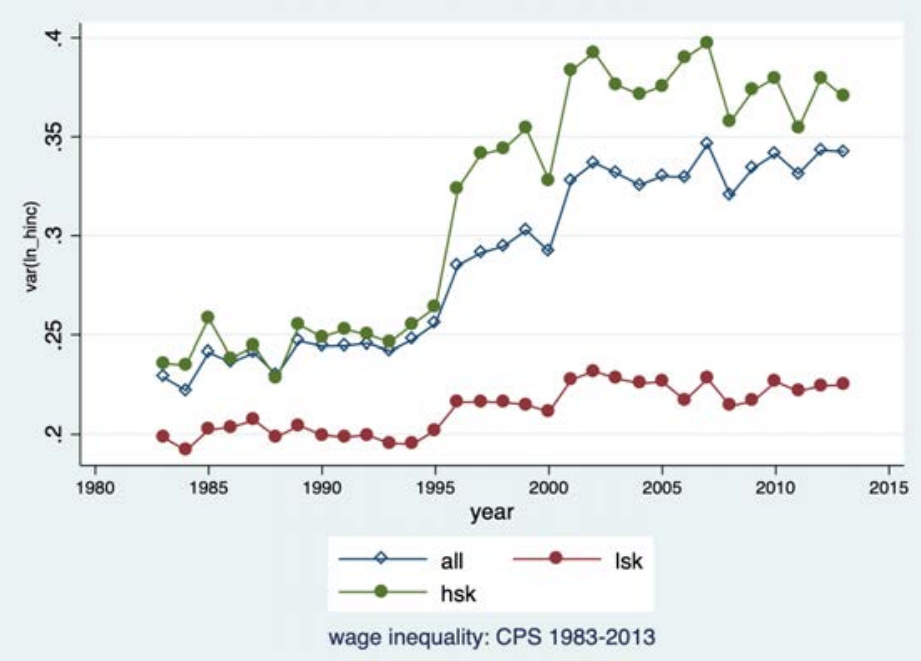

(a) Overall Wage Inequality

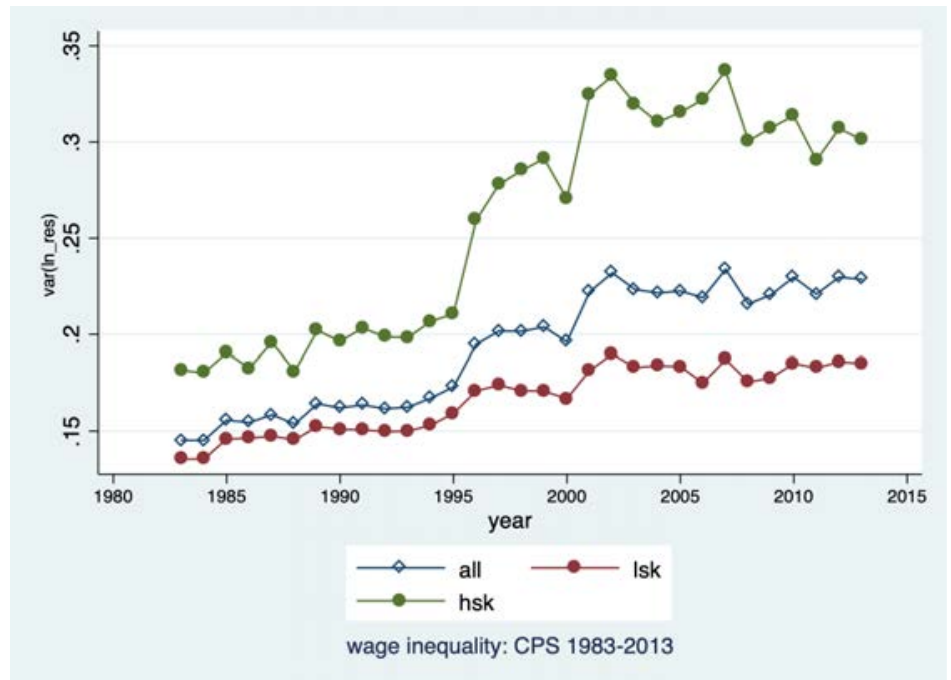

(b) Residual Wage Inequality

Figure 1: Wage inequality by education group

Notes: In the upper (lower) panel the inequality is measured as the variance of log value of hourly wage (wage residual). In both panels, the blue line represents the inequality for the whole sample, and green line only includes those highly educated. The red line is for low education group. Data source: March CPS from CEPR (1983-2013).

We take a closer examination of the inequality within the highly educated group in Figure 2. The upper panel presents the evolution of both the overall wage inequality and residual 


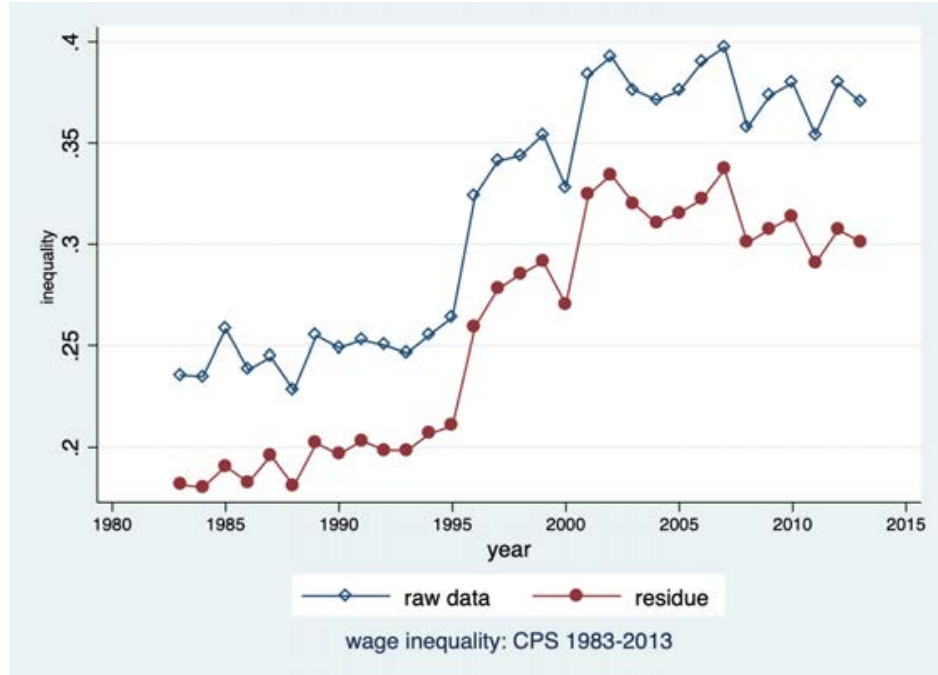

(a) Overall and Residual Wage Inequality

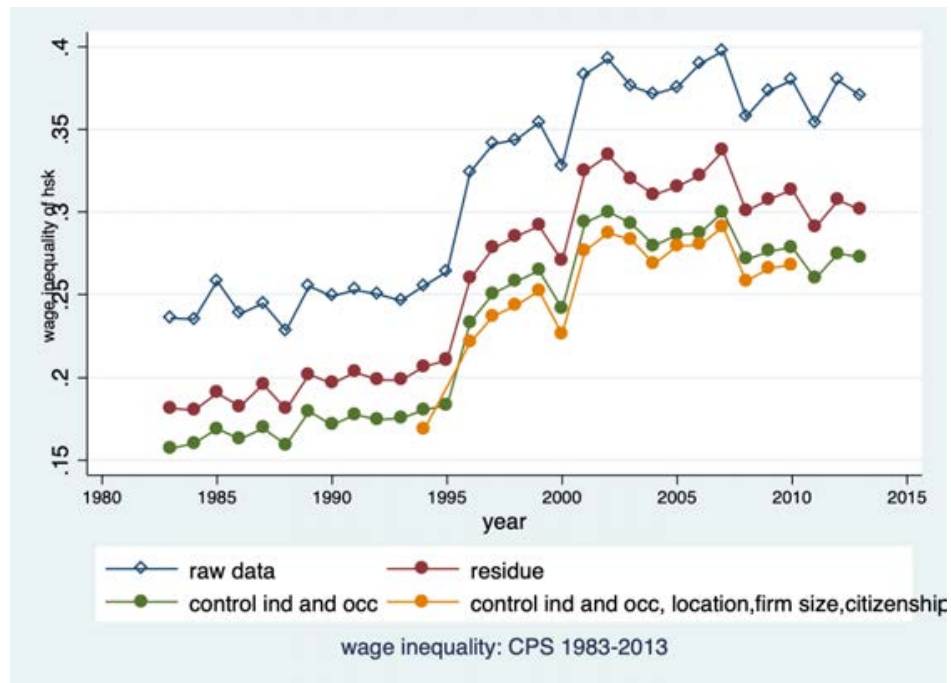

(b) Overall, Redidual and Within-job Wage Inequality

Figure 2: Residual Wage inequality of the highly educated

Notes: In both panels, the inequality is measured among the highly educated. The blue line represents the inequality of raw wage. The red line is residual wage inequality after controlling for only demographic characteristics. The green line is residual wage inequality after further controlling occupation and industry. The yellow line is residual wage inequality after further controlling for location, firm size, citizenship etc. Data source: March CPS from CEPR (1983-2013).

wage inequality, and it shows that residual wage inequality accounts around $80 \%$ of the overall wage inequality among the highly educated ones. This number is higher than the number commonly documented in the literature for the whole sample (e.g., Lemieux (2006)), in which individuals of different education levels are pooled together. The lower panel documents 
the trend of residual wage inequality when controlling more job characteristics including industry, occupation, location, firm size, citizenship and so on. It shows that controlling industry and occupation could explain $10 \%$ more, but the result does not change much when more variables such as location, firm size, are controlled. These facts suggest that the wage inequality within industry and occupation greatly contribute to the overall wage inequality. To consolidate this finding, we decompose residual wage inequality in the next subsection.

\subsection{Decomposition}

In this subsection, we decompose both the level and the change of residual wage inequality into two components: within-job and between-job inequality. A job is defined as an industryoccupation pair. Examples of jobs include sales in FIRE industry, managers in business, clerical workers in retails/wholesales trade and production workers in durable/nondurable goods, among others. To circumvent the miss-classification problem over different years due to changes in the content of either occupation or industry and the problem of empty cells, we use 1-digit code in both the industry and occupation, while checking occasionally the inclusion of 2-digit occupation when there is a potential concern.

Decomposition of the level Suppose there are $J$ jobs indexed as $j=1, \ldots J$. At job $j$, we denote $P_{j}$ to be the employment share, $V_{j}$ to be within-job wage inequality, and $E_{j}$ to be the average earnings. Then $\sum_{j} P_{j} V_{j}$ is the average within-job wage inequality weighted by

employment share, and $\sum_{j} P_{j}\left(\ln E_{j}-\sum_{j^{\prime}} P_{j^{\prime}} \ln E_{j^{\prime}}\right)^{2}$ is the weighted average of between-job wage inequality, where $\sum_{j^{\prime}} P_{j^{\prime}} \ln E_{j^{\prime}}$ is the weighted average of log earnings in the economy. Finally, the total wage inequality $\operatorname{var}(\ln E)$ can be decomposed into the between-job and within-job components as follows:

$$
\operatorname{var}(\ln E)=\sum_{j} P_{j} V_{j}+\sum_{j} P_{j}\left(\ln E_{j}-\sum_{j^{\prime}} P_{j^{\prime}} \ln E_{j^{\prime}}\right)^{2}
$$

The contribution of within-job wage inequality to the overall inequality is then the ratio of $\sum_{j} P_{j} V_{j}$ to $\operatorname{var}(\ln E)$.

It is shown in Figure 3 that the contribution of within-job inequality is persistently large. 


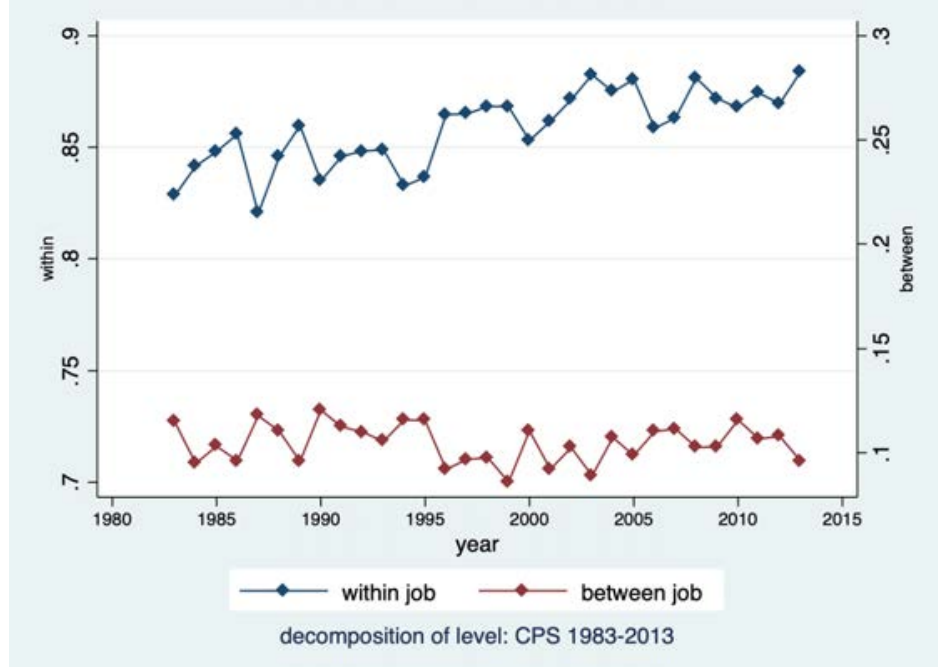

(a) 1-digit industry and 1-digit occupation code

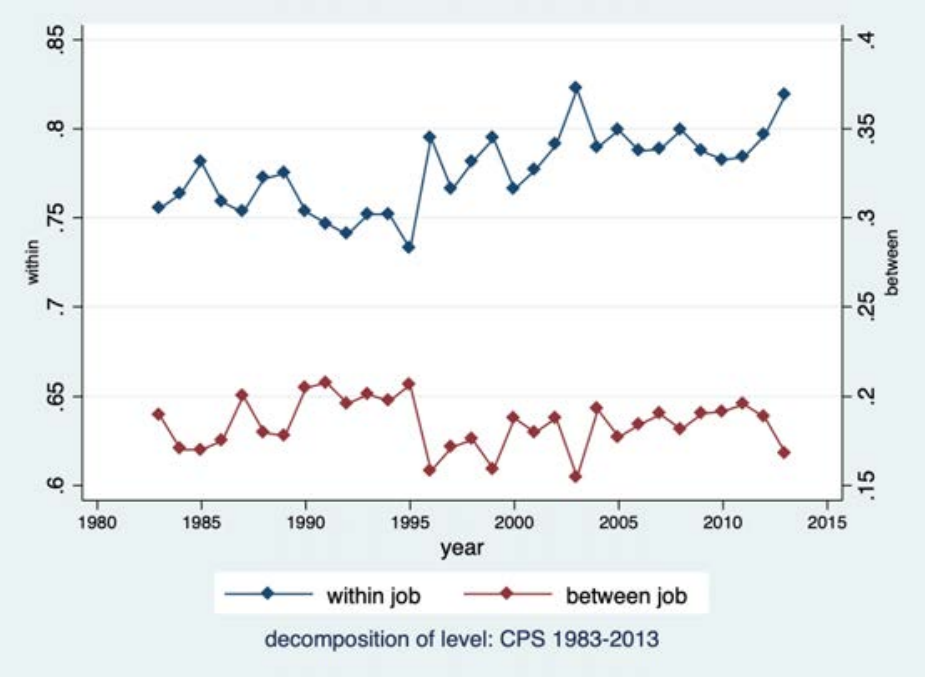

(b) 1-digit industry and 2-digit occupation code

Figure 3: Decomposition of residual wage inequality

Notes: Both panels show the proportion of within-job inequality to total residual inequality (blue) and the proportion of the between-job to total residual inequality (red). The upper panel is for 1-digit industry and occupation code, and the lower panel is for 1-digit industry and 2-digit occupation code. Data source: March CPS from CEPR (1983-2013).

Specifically, it is around $85 \%$ under the 1-digit industry and 1-digit occupation codes as shown in the upper panel. There may be a concern that the large contribution of within-job inequality may be a result of broad occupation categorization. We thus perform a robustness check using 1-digit industry and 2-digit occupation codes, As shown in the lower panel, the contribution of within-job inequality is still large, at about $80 \%$. More importantly, the 
contribution of the within-job component has been rising especially since the late 1990s.

Decomposition of the change We also decompose the changes of residual wage inequality over time into job related components. At job $j$ in year $t$, let $V_{j, t}$ be the wage inequality, $\ln E_{j, t}$ be the average log earnings, $P_{j, t}$ be the employment share, and $\ln E_{t}$ be the average $\log$ earning among all the jobs. Then the change of within-job wage inequality from $t$ to $t+1$ is $V_{j, t+1}-V_{j, t}$, the change of between-job wage inequality is $\left(\ln E_{t+1}-\ln E_{j, t+1}\right)^{2}-\left(\ln E_{t}-\right.$ $\left.\ln E_{j, t}\right)^{2}$, and the change of employment share is $P_{j, t+1}-P_{j, t}$. Therefore, the change of wage inequality between year $t+1$ and year $t, V_{t+1}-V_{t}$, can be decomposed into four components: the weighted average change of within-job wage inequality $\sum_{j=1}^{J} P_{j, t}\left[V_{j, t+1}-V_{j, t}\right]$, the weighted average change of between-job wage inequality $\sum_{j=1}^{J} P_{j, t}\left[\left(\ln E_{t+1}-\ln E_{j, t+1}\right)^{2}-\left(\ln E_{t}-\ln E_{j, t}\right)^{2}\right]$, the weighted average change of employment share $\sum_{j=1}^{J}\left(P_{j, t+1}-P_{j, t}\right)\left[V_{j, t}+\left(\ln E_{t}-\ln E_{j, t}\right)^{2}\right]$, and an interactive term that is the products of changes in the employment share and changes in the sum of within and between-job wage inequalities (to be simply referred to as "interaction" in the decomposition exercise),

$$
\sum_{j=1}^{J}\left(P_{j, t+1}-P_{j, t}\right)\left\{\left(V_{j, t+1}-V_{j, t}\right)+\left[\left(\ln E_{t+1}-\ln E_{j, t+1}\right)^{2}-\left(\ln E_{t}-\ln E_{j, t}\right)^{2}\right]\right\}
$$

Formally, we decompose the change of wage inequality as follows

$$
\begin{aligned}
V_{t+1}-V_{t} & =\sum_{j=1}^{J} P_{j, t}\left[V_{j, t+1}-V_{j, t}\right] \\
& +\sum_{j=1}^{J} P_{j, t}\left[\left(\ln E_{t+1}-\ln E_{j, t+1}\right)^{2}-\left(\ln E_{t}-\ln E_{j, t}\right)^{2}\right] \\
& +\sum_{j=1}^{J}\left(P_{j, t+1}-P_{j, t}\right)\left[V_{j, t}+\left(\ln E_{t}-\ln E_{j, t}\right)^{2}\right] \\
& +\sum_{j=1}^{J}\left(P_{j, t+1}-P_{j, t}\right)\left\{\left(V_{j, t+1}-V_{j, t}\right)+\left[\left(\ln E_{t+1}-\ln E_{j, t+1}\right)^{2}-\left(\ln E_{t}-\ln E_{j, t}\right)^{2}\right]\right\} .
\end{aligned}
$$

Similarly, the contribution of each component is defined as the ratio of its change to the total change in residual wage inequality. Table 1 presents the result between 1990 and 
2000. Under the benchmark definition of jobs using 1-digit industry and occupation code, the within-job component plays a dominant role, accounting for about $83 \%$ of the change in residual wage inequality. Again, we also check the result with 1-digit industry and 2-digit occupation code. The within-job component is still found to be the main driver, accounting for about $80 \%$ of the change in residual wage inequality.

Table 1: Decomposition of the changes in residual wage inequality: 1990-2000

\begin{tabular}{c|cccc}
\hline & Within-job & Between-job & Employment & Interaction \\
\hline 1-d code & $\mathbf{8 2 . 6 \%}$ & $9.2 \%$ & $2.7 \%$ & $3.5 \%$ \\
1-d ind, 2-d occ & $\mathbf{7 9 . 5 \%}$ & $8.1 \%$ & $8.5 \%$ & $0.3 \%$ \\
\hline
\end{tabular}

Notes: This table computes the contribution of within-job, between-job inequality, employment share and interactions to the changes in residual inequality from 1990 to 2000 . The row "1-d code" indicates 1-digit industry and occupation code, "1-d ind, 2-d occ" indicates 1-digit industry and 2-digit occupation code. Data source: March CPS from CEPR.

\subsection{Performance-pay incidence}

Since 1990 there is a growing number of performance-pay positions. Lazear (2000) has an example showing the coexistence of performance pay and fixed pay positions within the same job which we quote as follows:

"Safelite Glass Corporation is located in Columbus, Ohio, and is the country's largest installer of automobile glass. In 1994, Safeline, under the direction of CEO Garen Staglin and President John Barlow, implemented a new compensation scheme for the auto glass installers. Until January 1994, glass installers were paid an hourly wage rate, which did not vary in any direct way with the number of windows that were installed. During 1994 and 1995, installers were shifted from an hourly wage schedule to performance pay-specifically, to a piece-rate schedule. Rather than being paid for the number of hours that they worked, installers were paid for the number of glass units that they installed. The rates varied somewhat. On average installers were paid about $\$ 20$ per unit installed. At the time that the piece rates were instituted, the workers were also given a guarantee of approximately $\$ 11$ per hour. If their weekly pay came out to less than the guarantee, they would be paid the guaranteed amount. Many workers ended up in the guarantee range." 
Wage effect It has been shown that wage in performance-pay position is generally higher than that in fixed-pay position(e.g. Lemieux, MacLeod and Parent (2009)). In the literature, performance-pay incidence describes how likely the job will provide performance-pay position. Lemieux, MacLeod and Parent (2009) measure performance-pay incidence during 1976-1998 by estimating a linear probit model and the result is presented in Table A.1. In this paper, we follow their approach and estimate performance-pay incidence among 80 jobs separately for year 1990 and 2000 using data from PSID ${ }^{9}$.

Wage inequality effect We further show the relationship between performance-pay incidence and within-job wage inequality. Within-job wage inequality is again measured using CPS dataset. We classify industries and occupations each into 5 categories to have a consistent classification with those in PSID. In total there are 25 jobs are available. Merging PSID with CPS dataset, we finally have 24 jobs available. ${ }^{10}$

Figure 4 plots performance-pay incidence against within-job wage inequality for each of the 24 jobs in 1990 and 2000, respectively. It shows that there is a significant positive relationship between performance-pay incidence and within-job wage inequality. That is, jobs with higher performance-pay incidence usually have higher within-job wage inequality.

\subsection{Occupation/Job relatedness}

Job relatedness is measured as the correlation between the field of study from the highest degree and the occupation at the current job. In this subsection, we document the effects of job relatedness on both wage level and within-occupation wage inequality.

Wage effect Since industry information is not available in NSCG 1990 dataset, and thus we cannot have a consistent definition of job for both years. We have to turn to an alternative definition of job relatedness and instead measure within-occupation inequality. ${ }^{11}$ We use 3 -

\footnotetext{
${ }^{9}$ In each year, PSID dataset has 10 industries and 8 occupations, and thus in total 80 jobs.

${ }^{10}$ We drop 1 job with less than 30 observations.

${ }^{11}$ As a robustness check, we have also shown the relationship between job relatedness and within-job inequality in Figure A.4 using NSCG 2000 dataset. We have 1-digit 9 industries and 7 occupations, and in total 45 jobs after dropping jobs with less than 50 observations. The results remain qualitatively the same.
} 


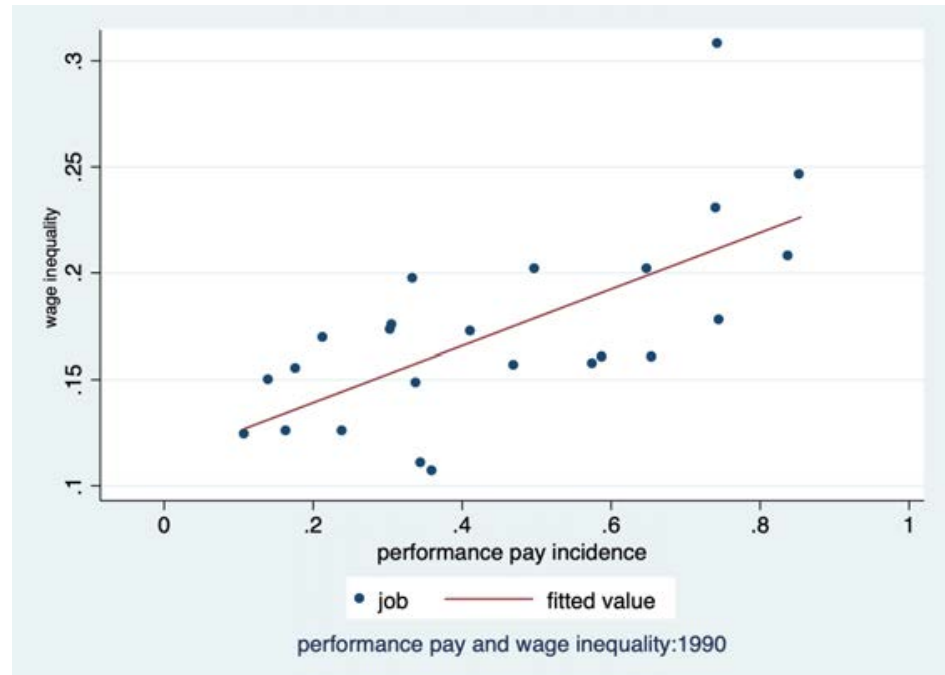

(a) 1990

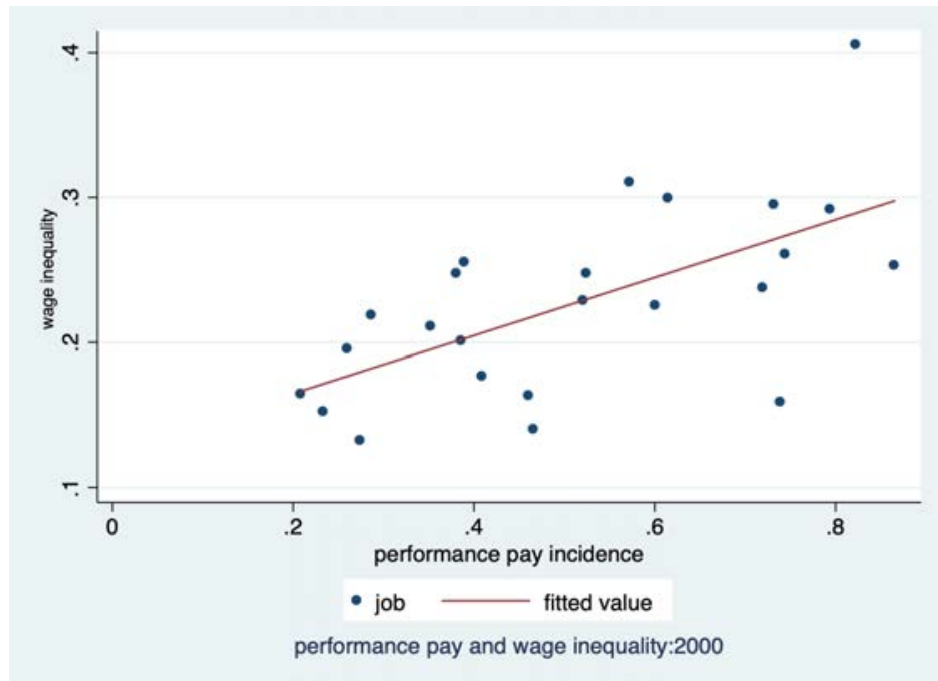

(b) 2000

Figure 4: Performance-pay incidence and within-job wage inequality

Notes: In both panels, each dot represents a job. In total we have 24 jobs. x-axis is performance-pay incidence. $\mathrm{y}$-axis is within-job wage inequality. Upper panel is based on 1990 data, and lower panel is based on 2000 data. Data source: PSID and March CPS.

digit occupation classification. There are 67 and 66 occupations from NSCG dataset in year 1990 and 2000, respectively. In particular, at each year we separately regress the log annual earnings against measures of job relatedness while controlling for demographic and occupational characteristics, major and other factors such as parents education and degree 


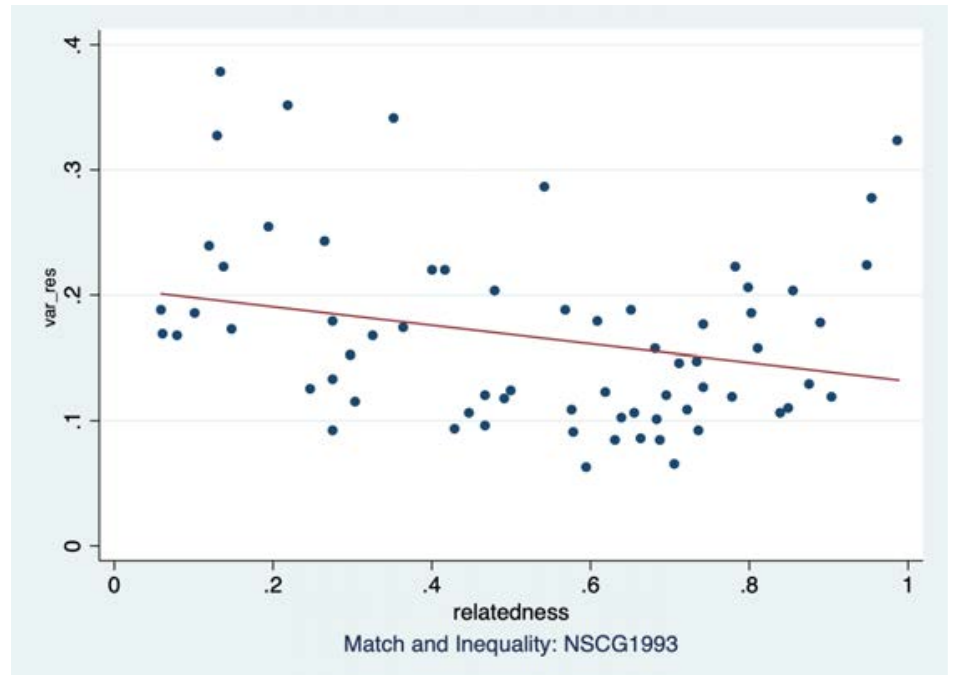

(a) 1990

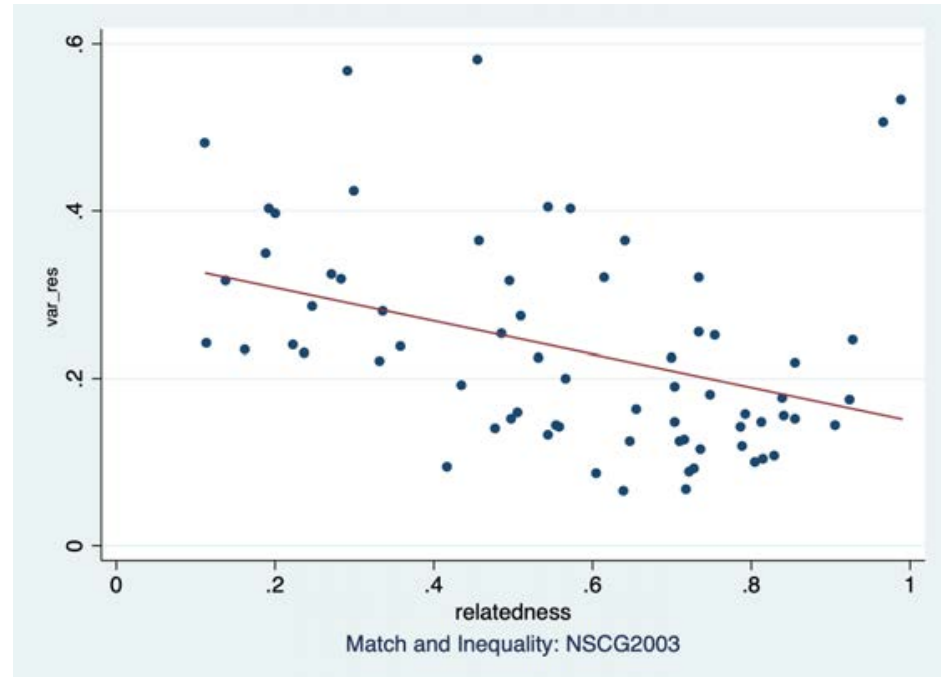

(b) 2000

Figure 5: Job relatedness and within-occupation wage inequality

Notes: In both panels, each dot represents an occupation(3-digit). $\mathrm{x}$-axis is job relatedness. $\mathrm{y}$-axis is the wage inequality within each occupation. The upper panel is based on 1990 data, and the lower panel is based on 2000 data. Data source: National Survey of College Graduate.

location:

$$
\ln (\text { earnings })_{i j m}=\beta D_{i}+\alpha Z_{j}+\theta M_{m}+\delta_{1} \text { close }_{j m}+\delta_{2} \text { some }_{j m}+\gamma X_{i}+\epsilon_{i j m},
$$

where $\ln (\text { earnings })_{i j m}$ is the log earnings of worker $i$ in occupation $j$ and major $m$. $D$ includes a vector of demographic variables (tenure, age, gender, race and etc.), $Z$ denotes 
the occupation, and $M$ denotes the major. close and some are dummies to indicate whether the occupation is closely or some related to the major, respectively. $X$ includes all other factors: parents education, degree location, work location and so on. ${ }^{12}$

Table A. 6 presents the main regression results. It shows that $\delta_{1}=0.171$ and $\delta_{2}=0.118$ in $1990 ; \delta_{1}=0.229$ and $\delta_{2}=0.170$ in 2000 . The fact that $\delta_{1}>\delta_{2}>0$ suggests that there exists a positive and significant relationship between job relatedness and earnings. In comparison with worker whose occupation is not related to his major, worker whose occupation is somewhat related or related to the major receives $11.8 \%$ or $17.1 \%$ higher annual earning in 1990, respectively. Similar pattern can be found in year 2000, in addition, the effect of job relatedness on wage becomes larger in 2000 than that in 1990 . This sheds light on the potential of explaining rising wage inequality.

Wage inequality effect To show the relationship between job relatedness and wage inequality, we measure the job relatedness by the percentage of workers who reported "closely related". Figure 5 plots job relatedness and wage inequality across occupations under 3-digit classification. In this figure, each point represents one occupation and wage inequality is residual wage inequality in NSCG. It shows that there is a significant negative relationship between job relatedness and within-occupation wage inequality in both 1990 and 2000. As a robustness check, we have also plot the relation between the two under the 2-digit occupation classification in Figure A.3. The results remain.

\subsection{A first look at the impact on wage inequality}

The evidence established enables us to take a first look at how performance-pay incidence and job relatedness may affect within-job wage inequality. We restrict the analysis to a selection of 24 jobs, which commonly show up in CPS, PSID and NSCG dataset.

By comparing data from 1990 and 2000 as depicted in Figure 6, we learn that performancepay incidence rises in 23 of 24 jobs with the only (sizable) fall in the business-sales pair. On the contrary, job relatedness falls in 19 of 24 jobs, with all rises by negligible margins.

\footnotetext{
${ }^{12}$ Guvenen et al. (2020) show that skill mismatch has significant and persistent negative effect on the wages and earnings as copied in Table A.2.
} 
Thus, given the relationships identified in the previous subsections, namely, the positive relationship between performance-pay incidence and within-job wage inequality and the negative relationship between job relatedness and within-job wage inequality, we expect wage inequality to rise when performance-pay incidence is higher but job relatedness is lower.

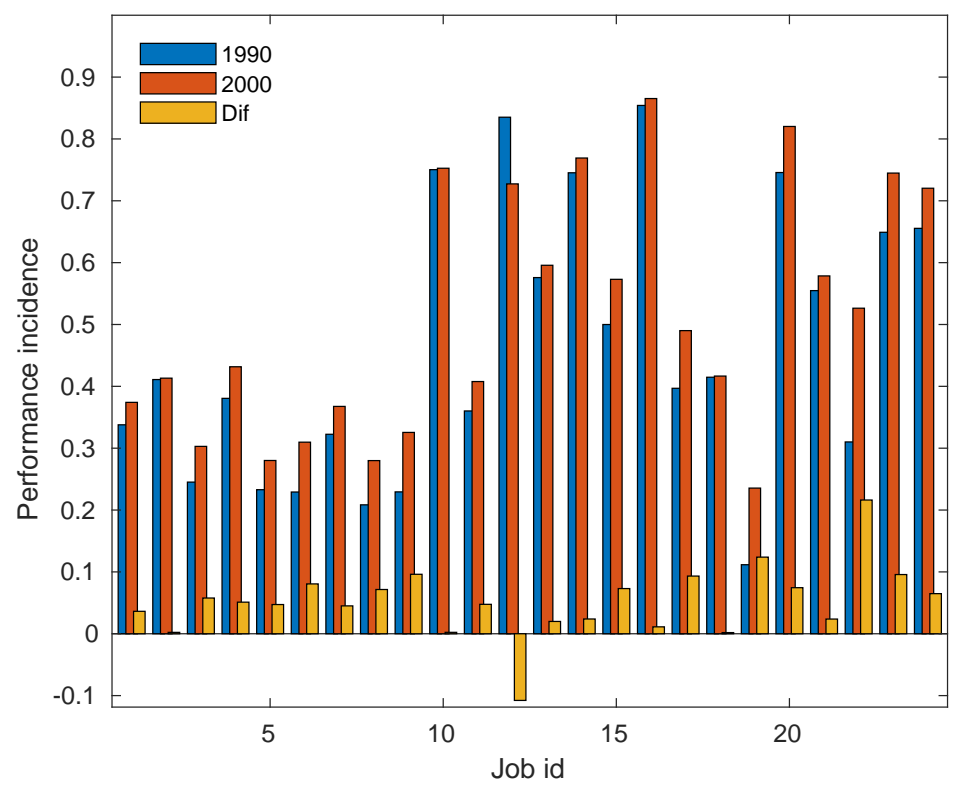

(a) Changes in Performance-pay Incidence

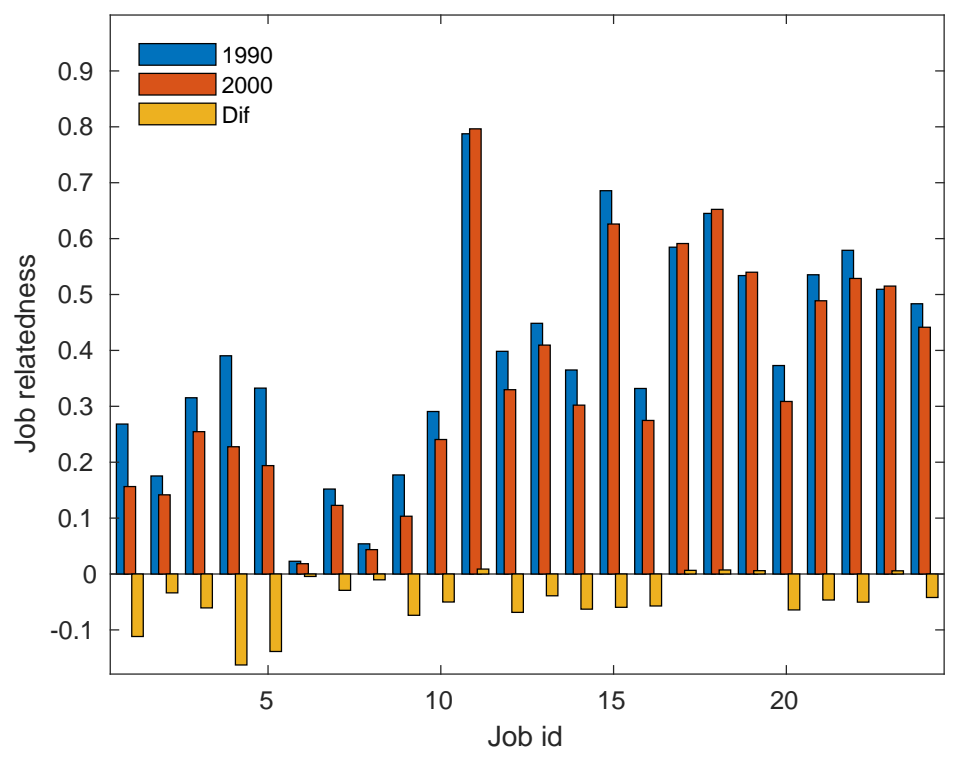

(b) Changes in Job Relatedness

Figure 6: Changes in performance-pay incidence and Job relatedness by job

Notes: We report the levels of performance-pay incidence and job relatedness in 1990 and 2000, and their changes from 1990 to 2000 among a selection of 24 jobs. 
To understand the impact of these two channels on wage inequality, we thus build a sorting equilibrium model to which we now turn.

\section{The model}

The empirical analysis have only established simple correlation between performance-pay incidence or job relatedness and within-job inequality. However, in the reality, job relatedness may in turn affect performance-pay incidence, and within-job inequality may also influence the magnitude of job relatedness and performance-pay incidence. This thereby requires a model to discipline the interactions between them.

Environment There are $J$ jobs available in the economy, defined as industry-occupation pairs and indexed by $j=1,2, \ldots J$. At each job, two types of positions are offered: fixed-pay $(F P)$ position and performance-pay $(P P)$ position. Workers are heterogeneous in innate ability $a$ and will choose jobs, positions and efforts to maximize utility. Job characteristics and worker's ability are both public information.

Performance-pay position A worker's efficient labor supply at performance-pay position depends on his ability $a$, the job-specific productivity $A$, an idiosyncratic productivity premium $\eta$, and his effort level $e$. Specifically, the efficient labor supply is given by,

$$
h=\text { Aane }
$$

Ability $a$ follows a Pareto distribution $a \sim G(a)=1-\left(\frac{1}{a}\right)^{\theta_{a}}, a \geq 1, \theta_{a}>2$, with the minimum ability normalized to 1 . The assumption of $\theta_{a}>2$ is to guarantee finite variance, which is essential for the analysis of wage inequality measured by the variance of logged wage. To capture the idea of job relatedness in the data, we consider that with probability $p_{j} \in(0,1)$ the worker may find job $j$ related to his major. Under this circumstance, the worker gets to draw an idiosyncratic productivity premium $s$ from a job-specific Pareto distribution defined over $[1, \infty)$, otherwise the productivity premium is 1 . Formally, the 
idiosyncratic productivity premium $\eta$ of job $j$ obeys

$$
\eta=\left\{\begin{array}{ll}
s & \text { with probability } p_{j} \\
1 & \text { with probability } 1-p_{j}
\end{array}, \text { and } s \sim F(s)=1-\left(\frac{1}{s}\right)^{\theta_{s j}}, s \geq 1, \theta_{s j}>2\right.
$$

where $\theta_{s j}$ captures the dispersion of productivity premium distribution at job $j$, and similarly the assumption of $\theta_{s j}>2$ is maintained.

We denote $H_{j}(a, \eta)$ to be the joint distribution of the ability and the productivity premium at job $j$. The total efficient labor supply in performance-pay position of job $j$ are:

$$
H_{j p}=\int_{a \in D_{j p}} \int_{\eta} h_{j p}(a, \eta) d H_{j}(a, \eta),
$$

where $D_{j P}$ is the ability domain for workers, $h_{j p}(a, \eta)$ is the efficient labor supply from a worker of ability $a$ and productivity premium $\eta$. To simplify the analysis, we further assume the distribution of ability and productivity premium are independent. That is, $H_{j}(a, \eta)=G(a) H_{j}(\eta)$, where $H_{j}(\eta)$ is the distribution of the productivity premium, and it equals $H_{j}(\eta)=\left(1-p_{j}\right)+p_{j} F_{j}(\eta)$.

Fixed-pay position Individual worker's efficient labor supply at fixed-pay position depends neither on the innate ability nor the effort level. It is assumed to be only linear in the job-specific productivity. Specifically, at job $j$ the efficient labor supply from a worker in fixed-pay position is $A_{j}$. The total efficient labor supply in fixed-pay position of job $j$ are thus:

$$
H_{j F}=A_{j} N_{j F}
$$

where $N_{j F}$ is the employment level at fixed-pay position of job $j$.

Production and payment The production function in job $j$ is a CES aggregator of the efficient labor supply from performance-pay position and fixed-pay position. Specifically, the output of job $j$ is given by,

$$
Y_{j}=\left[\alpha_{j} H_{j F}^{\gamma}+\left(1-\alpha_{j}\right) H_{j p}^{\gamma}\right]^{\frac{1}{\gamma}}, \gamma<1
$$


where $\frac{1}{1-\gamma}$ is the elasticity of substitution between the labor supply from the two positions - they are substitutable (complementary) if $\gamma>0(\gamma<0) ; \alpha_{j}$ is job specific to reflect the intensity of fixed-pay position at each job.

We denote $w$ to be the wage rate per worker at fixed-pay position. In each job $j$, given wage rate $w$, the representative firm decides the employment level at fixed-pay position to maximize the profit net of payment to workers at fixed-pay position. That is,

$$
\max _{N_{j F}} Y_{j}-w N_{j F}
$$

It is straightforward to show $N_{j F}$ satisfies:

$$
N_{j F}=\left[\frac{\left(\frac{w}{\alpha_{j} A_{j}}\right)^{\frac{\gamma}{1-\gamma}}-\alpha_{j}}{1-\alpha_{j}}\right]^{-\frac{1}{\gamma}} \frac{H_{j P}}{A_{j}} \equiv \frac{\chi_{j} H_{j P}}{A_{j}} .
$$

We show in Appendix D that the total payment to workers at fixed-pay position, $\frac{w}{A_{j}} \chi_{j} H_{j P}$, is equivalent to:

$$
E_{j F}=\tilde{\alpha}_{j} \tilde{A}_{j} H_{j P}
$$

where $\tilde{A}_{j}=\left[\alpha_{j} \chi_{j}^{\gamma}+\left(1-\alpha_{j}\right)\right]^{\frac{1}{\gamma}}$, and $\tilde{\alpha}_{j}=\frac{\alpha_{j} \chi_{j}^{\gamma}}{\alpha_{j} \chi_{j}^{\gamma}+\left(1-\alpha_{j}\right)}$. We also show in Appendix D that the total output can be expressed as $Y_{j}=\tilde{A}_{j} H_{j P}$. Therefore, the residual profit at performancepay position is $E_{j P}=\left(1-\tilde{\alpha}_{j}\right) \tilde{A}_{j} H_{j P}$.

Firms and workers at performance-pay position share the residual profit. We assume workers' bargaining power is $\mu$. Therefore, the total payment to workers at performance-pay position is $E_{j P}=\mu\left(1-\tilde{\alpha}_{j}\right) \tilde{A}_{j} H_{j P}$, and the payment for an individual worker of ability $a$ and productivity premium $\eta$ at performance-pay position is thus $\mu\left(1-\tilde{\alpha}_{j}\right) \tilde{A}_{j} A_{j} a \eta e_{j}(a, \eta)$.

Workers A worker's utility positively depends on his own consumption $c$, and negatively depends on his effort level $e$. In addition, for workers at performance-pay position, he also 
suffers from a job-specific disutility of being monitored. ${ }^{13}$ We further assume worker's utility function is linear in consumption and quadratic in his effort level. Specifically, worker's utility function from working at performance-pay position of job $j$ takes form:

$$
U_{j}^{P}=c-\frac{1}{2} b e^{2}-M_{j}
$$

where $b$ measures the degree of disutility on effort and $M_{j}$ is the disutility level from job $j$.

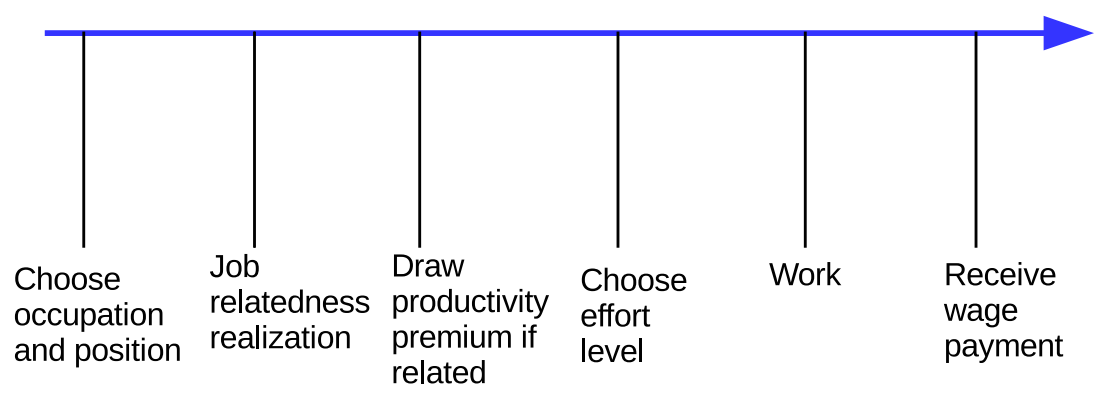

Figure 7: Timeline

Workers make decision on jobs, positions and efforts. We summarize the timeline of worker's decision in Figure 7. The worker chooses the job and the position before the realization of job relatedness and the productivity premium. In contrast, the optimal effort

\footnotetext{
${ }^{13}$ The purpose for monitoring is to prevent workers in performance-pay position from shirking. To simplify the analysis, we make the following two assumptions. First, when there is shirking, worker's effort decreases to $(1-\delta)$ of the optimal effort level. Second, we assume the following condition which rules out the equilibrium with shirking, for any $j$

$$
1>\delta^{2}>\frac{2 \mu b M_{j}}{\left[\mu\left(1-\tilde{\alpha}_{j}\right) \tilde{A}_{j} A_{j}\right]^{2}} .
$$
}


level is chosen after the worker observes the outcome of job relatedness and the productivity premium.

Before the realization of the job relatedness and the productivity premium, the expected utility from performance-pay position at job $j$ is thus

$$
E U_{j}^{P}(a)=E_{\eta}\left[U_{j}^{P}(a, \eta)\right]
$$

To simplify the analysis, we assume fixed outside option such that the utility from working at fixed-pay position is constant, denoted as $\underline{U}$. Finally, a worker chooses the job and position which delivers the highest expected utility.

$$
E V(a)=\max _{j}\left\{\underline{U}, E U_{j}^{P}(a)\right\}
$$

Thus, a fixed-pay position is chosen by a worker of ability $a$ if $\underline{U}>\max _{j}\left\{E U_{j}^{P}(a)\right\}$; otherwise, a worker of ability $a$ would choose a performance-pay position at job

$$
j^{*}(a)=\arg \max _{j}\left\{E U_{j}^{P}(a)\right\} .
$$

\section{Theoretical analysis}

\subsection{Equilibrium}

Given job-specific characteristics $\left\{A_{j}, \alpha_{j}, M_{j}, \theta_{s j}, p_{j}\right\}$, a sorting equilibrium is described by the wage rate per unit of raw labor $w$ and the labor allocation across jobs and positions $\left\{D_{j F}, D_{j p}\right\}$ such that:

1. Given the wage rate $w$ per unit of raw labor supply, and the efficient labor supply from performance-pay position $H_{j P}$, firms decide the employment at fixed-pay position $N_{j F}$ to maximize their profits as in equation (7).

2. Given the employment at fixed-pay position, workers optimally choose jobs and positions $\left\{D_{j F}, D_{j p}\right\}$ as in equation (10). 
3. The labor market clears:

$$
\sum_{j} \int_{a \in\left\{D_{j F} \cup D_{j P}\right\}} d G(a)=1
$$

where the total amount of labor force is normalized to be 1 .

\subsection{Analytical Results}

In the following, we solve worker's decision in a backward fashion. Specifically, a worker of ability $a$ at performance-pay position of job $j$ after realizing the productivity premium $\eta$ chooses effort to maximize his utility:

$$
U_{j}^{P}(a, \eta)=\max _{e} c_{j}(a, \eta, e)-\frac{1}{2} b e^{2}-\mu M_{j}
$$

Consumption $c_{j}$ equals to the total earnings:

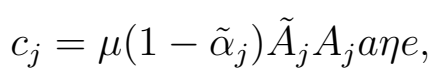

and thus the resulting effort level is:

$$
e_{j}(a, \eta)=\mu\left(1-\tilde{\alpha}_{j}\right) \tilde{A}_{j} A_{j} a \eta / b
$$

Given the effort level above, worker's efficient labor supply is thus:

$$
h_{j p}(a, \eta)=\frac{\mu\left[\left(1-\tilde{\alpha}_{j}\right) \tilde{A}_{j} A_{j} a \eta\right]^{2}}{b} .
$$

and the ex-post utility from working at job $j$ can be derived as:

$$
U_{j}^{P}(a ; \eta)=\frac{1}{2 b}\left(\left(1-\tilde{\alpha}_{j}\right) \tilde{A}_{j} A_{j} \eta \mu a\right)^{2}-\mu M_{j}
$$

and the expected utility is

$$
E U_{j}^{P}(a)=\tilde{C}_{j} a^{2}-\tilde{M}_{j} .
$$


where

$$
\begin{aligned}
\tilde{C}_{j} & =\frac{1}{2 b}\left(\left(1-\tilde{\alpha}_{j}\right) \tilde{A}_{j} A_{j} \mu\right)^{2} E_{j}\left(\eta^{2}\right), \\
\tilde{M}_{j} & =\mu M_{j}
\end{aligned}
$$

and

$$
E_{j}\left(\eta^{2}\right)=p_{j} \frac{\theta_{s j}}{\theta_{s j}-2}+1-p_{j}
$$

\subsection{An equilibrium with positive assortative sorting}

To circumvent the potential issues associated with multiple equilibria in a general setting, we restrict our attention to the case of monotone job ranking under which we order $n$ such that $\left\{\tilde{M}_{n}\right\}$ and $\left\{\tilde{C}_{n}\right\}$ are increasing sequences of $n .{ }^{14}$ In this case, we are able to characterize the sorting equilibrium.

We start with the following lemma to show that within performance-pay position, workers of higher ability will choose the job of larger index.

Lemma 1 If a worker of ability a chooses to work at performance-pay position of job $k$, then workers of ability $a^{\prime}>$ a will prefer performance-pay position at any job $n \geq k$ than at job $k$.

We further impose the following assumption to ensure the existence of a sorting equilibrium.

Assumption 1: $\frac{\tilde{M}_{n}-\tilde{M}_{n-1}}{\tilde{C}_{n}-\tilde{C}_{n-1}}$ is increasing in $n$ for all $n>1$.

When the assumption above holds, we can further characterize workers' preferences over jobs within performance-pay position in the following lemmas.

Lemma 2 Under Assumption 1, workers of ability $a \in\left(\sqrt{\frac{\tilde{M}_{n}-\tilde{M}_{n-1}}{\tilde{C}_{n}-\tilde{C}_{n-1}}}, \sqrt{\frac{\tilde{M}_{n+1}-\tilde{M}_{n}}{\tilde{C}_{n+1}-\tilde{C}_{n}}}\right)$ prefer

\footnotetext{
${ }^{14}$ In the remaining of this section, we re-label job index as $n=1,2 \ldots J$ to denote the ranking of jobs in the sorting equilibrium.
} 
performance-pay position at job $n$ to that at $n-1$ and $n+1$.

Lemma 3 Under Assumption 1, if a worker of ability a prefers performance-pay position at job $n$ to $n-1$, then he also prefers performance-pay position at job $n$ to any job $k<n-1$.

Lemma 4 Under Assumption 1, if worker of ability a prefers performance-pay position at job $n$ to $n+1$, then he also prefers performance-pay position at job $n$ to any job $k>n+1$.

The proof of the above three lemmas can be found in Appendix C. These lemmas together imply that conditional on workers at performance-pay position, workers of ability $a \in$ $\left(\sqrt{\frac{\tilde{M}_{n}-\tilde{M}_{n-1}}{\tilde{C}_{n}-\tilde{C}_{n-1}}}, \sqrt{\frac{\tilde{M}_{n+1}-\tilde{M}_{n}}{\tilde{C}_{n+1}-\tilde{C}_{n}}}\right)$ would find it optimal to work in job $n$. Denote $a_{n}^{*}:=\sqrt{\frac{\tilde{M}_{n}-\tilde{M}_{n-1}}{\tilde{C}_{n}-\tilde{C}_{n-1}}}$ to be the cutoff ability, we can thus conclude that workers of ability $a \in\left[a_{n}^{*}, a_{n+1}^{*}\right)$ would prefer performance-pay position at job $n$ than at any other jobs.

The previous analysis are restricted to workers at performance-pay position. In the following, we explore how workers choose between performance-pay position and fixed-pay position. We need to impose the following additional assumption.

Assumption 2: $\exists \underline{a}<a_{2}^{*}$ s.t. $\tilde{C}_{1} \underline{a}^{2}-\tilde{M}_{1}<\underline{U}<\tilde{C}_{1}\left(a_{2}^{*}\right)^{2}-\tilde{M}_{1}$ holds.

Lemma 5 Under Assumption 2, workers of $a \in\left[\underline{a},\left(\frac{\underline{\underline{U}+\tilde{M}_{1}}}{\tilde{C}_{1}}\right)^{1 / 2}\right)$ choose to work in fixed-pay position, and workers of $a \in\left[\left(\frac{\underline{\underline{U}+\tilde{M}_{1}}}{\tilde{C}_{1}}\right)^{1 / 2}, a_{2}^{*}\right)$ choose to work in performance-pay position of job 1 .

Combining all the Lemmas above yields the following proposition.

Proposition 6 Under Assumptions 1 and 2, there exists a sorting equilibrium that is positive assortative both within and across jobs. 
(i) Sorting across jobs: Workers of ability $a \in\left(\sqrt{\frac{\tilde{M}_{n}-\tilde{M}_{n-1}}{\tilde{C}_{n}-\tilde{C}_{n-1}}}, \sqrt{\frac{\tilde{M}_{n+1}-\tilde{M}_{n}}{\tilde{C}_{n+1}-\tilde{C}_{n}}}\right)$ find it optimal to work at performance-pay position of job $n>2$, whereas workers of a $\in$ $\left[\left(\frac{\underline{U}+\tilde{M}_{1}}{\tilde{C}_{1}}\right)^{1 / 2}, a_{2}^{*}\right)$ chooses to work in performance-pay position of job 1 .

(ii) Sorting within jobs: Workers of $a \in\left[\underline{a},\left(\frac{\underline{U}+\tilde{M}_{1}}{\tilde{C}_{1}}\right)^{1 / 2}\right)$ choose to work in fixed-pay position of any job.

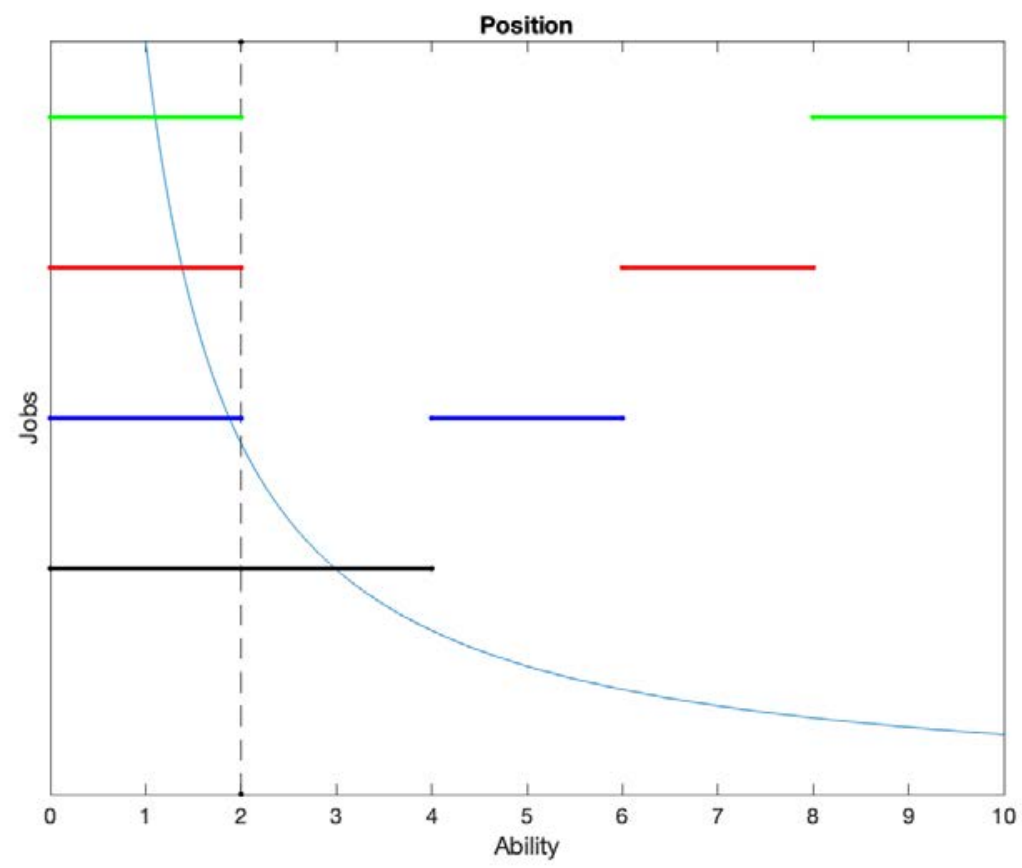

Figure 7: Job and position choice

Notes: The x-axis represents the ability level. y-axis represents 4 jobs in different colors. The top axis represents the two positions: on the left of the dash line is fixed-pay position, and on the right of the line is performance-pay position. The solid blue line represents the ability distribution. Hence in the figure there are four cutoff abilities which are $a_{\min }=a_{1}^{*}=2, a_{2}^{*}=4, a_{3}^{*}=6, a_{4}^{*}=8$. Then workers will be indifferent between jobs in fixed-pay position if $a<a_{1}^{*}$, and choose job $n$ with performance-pay if $a_{n}^{*} \leq a<a_{n+1}^{*}, n=1,2,3,4$.

An illustration of job and position choices To illustrate the sorting equilibrium defined above, we make a simple example in Figure 7. There are four jobs (job one (green), job two (red), job three (blue), job four (black)), and hence there are four cutoff abilities which, in the figure, are $a_{\min }=a_{1}^{*}=2, a_{2}^{*}=4, a_{3}^{*}=6, a_{4}^{*}=8$. Workers will work in fixed-pay position if $a<a_{1}^{*}$, and choose performance-pay position of job $n$ if $a_{n}^{*} \leq a<a_{n+1}^{*}, n=1,2,3,4$. 
Therefore, in each job there are some workers in performance-pay position and others in fixed-pay position.

\subsection{Wage inequality}

Denote performance-pay incidence as $n_{p}$ and the fraction of related jobs as $p_{n}$, whose effects on within-job wage inequality will be characterized in this subsection. Within-job wage inequality at any job $n$, denoted $V_{n}$, can be decomposed into the following within- and between-position component:

$$
V_{n}=n_{p} V_{n p}+n_{p}\left(1-n_{p}\right)\left(\ln E_{n p}-\ln E_{n F}\right)^{2}
$$

where $V_{n p}$ is the wage inequality within performance-pay position of job $n$, and $\ln E_{n p}-\ln E_{n F}$ captures the difference in average wages between performance-pay $\left(\ln E_{n p}\right)$ fixed-pay $\left(\ln E_{n F}\right)$ position.

Within performance-pay position, the mean of log wage is the weighted average of wages among related(ln $\left.E_{n p s}\right)$ and un-related workers(ln $\left.E_{n p m}\right)$ :

$$
\ln E_{n p}=p_{n} \ln E_{n p s}+\left(1-p_{n}\right) \ln E_{n p m}
$$

where

$$
\begin{gathered}
\ln E_{n p s}=\frac{1}{N_{n p}} \int_{a_{n}^{*}}^{a_{n+1}^{*}} \int_{s} \ln \left\{\frac{\left[\mu\left(1-\tilde{\alpha}_{n}\right) \tilde{A}_{n} A_{n} a s\right]^{2}}{b}\right\} d H_{n}(a, s), \\
\ln E_{n p m}=\frac{1}{N_{n p}} \int_{a_{n}^{*}}^{a_{n+1}^{*}} \ln \left\{\frac{\left[\mu\left(1-\tilde{\alpha}_{n}\right) \tilde{A}_{n} A_{n} a\right]^{2}}{b}\right\} d G(a) .
\end{gathered}
$$

Similar to the definition of $V_{n}$, the inequality within performance pay position can be further decomposed into inequality within related $\left(V_{n p s}\right)$, unrelated $\left(V_{n p m}\right)$ workers and inequality between them $\left(\ln E_{n p s}-\ln E_{n p m}\right)$ :

$$
V_{n p}=p_{n} V_{n p s}+\left(1-p_{n}\right) V_{n p m}+p_{n}\left(1-p_{n}\right)\left(\ln E_{n p s}-\ln E_{n p m}\right)^{2},
$$


where

$$
\begin{aligned}
V_{n p s} & =\operatorname{var}_{n}\left(\ln \left[\frac{\left(\mu\left(1-\tilde{\alpha}_{n}\right) \tilde{A}_{n} A_{n} a s\right)^{2}}{b}\right]\right) \\
& =\frac{1}{N_{n p}} \int_{a_{n}^{*}}^{a_{n+1}^{*}} \int_{s}\left\{\ln \left[\frac{\left(\mu\left(1-\tilde{\alpha}_{n}\right) \tilde{A}_{n} A_{n} a s\right)^{2}}{b}\right]-\ln E_{n p s}\right\}^{2} d H_{n}(a, s)
\end{aligned}
$$

and

$$
\begin{aligned}
V_{n p m} & =\operatorname{var}_{n}\left(\ln \left[\frac{\left(\mu\left(1-\tilde{\alpha}_{n}\right) \tilde{A}_{n} A_{n} a\right)^{2}}{b}\right]\right) \\
& =\frac{1}{N_{n p}} \int_{a_{n}^{*}}^{a_{n+1}^{*}}\left\{\ln \left[\frac{\left(\mu\left(1-\tilde{\alpha}_{n}\right) \tilde{A}_{n} A_{n} a\right)^{2}}{b}\right]-\ln E_{n p m}\right\}^{2} d G(a) .
\end{aligned}
$$

Performance-pay incidence To explore the impacts of performance-pay incidence on within-job wage inequality, we can obtain the following proposition:

Proposition 7 If $n_{p}<\frac{1}{2}$, then $V_{n}$ is increasing in performance pay incidence $\left(n_{p}\right)$.

The proposition above establishes a positive relationship between performance-pay incidence and within-job inequality. Everything else being equal, jobs with larger share of employment in performance-pay position have higher wage inequality.

Job relatedness We further analytically examine the role of job relatedness played in with-job wage inequality in the following proposition.

Proposition 8 A sorting equilibrium possesses the following properties.

(i) The wage difference between performance-pay and fixed-pay position is increasing with job relatedness $p_{n}$.

(ii) The wage inequality within performance-pay position $V_{n p}$ is increasing with with job relatedness $p_{n}$. 
However, the relationship between job relatedness and within-job wage inequality remains ambiguous. To see this, we derive

$$
\frac{\partial V_{n}}{\partial p_{n}}=n_{p} \underbrace{\frac{\partial V_{n p}}{\partial p_{n}}}_{>0}+2 n_{p}\left(1-n_{p}\right) \underbrace{\left(\ln E_{n p}-\ln E_{n F}\right)}_{>0} \underbrace{\frac{\partial \ln E_{n p}}{\partial p_{n}}}_{>0}+\underbrace{\frac{\partial n_{p}}{\partial p_{n}}\left[V_{n p}+\left(1-2 n_{p}\right)\left(\ln E_{n p}-\ln E_{n F}\right)^{2}\right]}_{?} .
$$

As shown in Proposition 8, the first two terms are positive. Yet, in sorting equilibrium, greater job relatedness need not induce higher performance-pay incidence. As shown in Section 2.6, from 1990 to 2000, we have seen a drop in job relatedness and a rise in performancepay incidence. In this case, the third term becomes negative if $n_{p}<1 / 2$, which may outweigh the first two terms, leading to an overall negative relationship between job relatedness and wage inequality as observed in data (recall Section 2.6).

\section{Quantitative Analysis}

We perform quantitative analysis in this section. We first calibrate the model to mimic inequality patterns of the US economy in 2000. The calibrated model successfully matches several key job-specific moments in the data. To evaluate the contributions of different potential channels to changes in inequality from 1990 to 2000, we then conduct a decomposition exercise.

\subsection{Calibration}

We calibrate the benchmark model to the US economy in 2000. Similar to Section 2.6, we focus on a selection of 24 jobs, which can be observed in CPS, PSID and NSCG dataset. $\mu$ governs workers' bargaining power at performance-pay position, and we let it be 0.6. $\theta_{a}$ is the shape parameter of the Pareto distribution for workers' innate abilities. We assign a value of 8.0 to it so that the 90-10 earning ratio in our calibrated economy is roughly at 5.0. $\gamma$ captures the elasticity of substitution between efficient labor supply in the production function. We target it to match between-job inequality. $b$ is the parameter governing the disutility from exerting effort. We normalize it such that the least talented individual at 
performance-pay position chooses to exert the same effort level as those in fixed-pay position, i.e., the minimum effort $\left(e_{\min }\right)$.

In total we have five job-specific series: $\left\{A_{j}, M_{j}, p_{j}, \alpha_{j}, \theta_{s j}\right\}_{j=1}^{J} \cdot\left\{M_{j}\right\}$ is the job-specific monitor costs, and we calibrate it to match the fraction of workers at performance-pay position in each job. $\left\{p_{j}\right\}$ captures job relatedness, and we directly use the estimation results from Section 2 using data from NSCG. $\left\{\alpha_{j}\right\}$ is the coefficient on the raw labor supply in the production function. We calibrate it to match the employment share of performancepay position at each job. $\left\{A_{j}\right\}$ is the job-specific productivities, and we have it to match the average pay relative to the overall mean at each job ${ }^{15}$. Finally, $\left\{\theta_{s j}\right\}$ is the job-specific shape parameter that governs the distribution of the productivity premium. We choose them to match within-job inequality. We summarize the parameter values and their targets in Table 2. In Table 3, we report the model predicted within-job, between-job and overall inequalities as opposed to the data counterpart in 2000. The model has reasonably matched the untargeted between-job inequality and overall inequality.

Table 2: Benchmark Parameterizations

\begin{tabular}{llcc}
\hline Para. & Targets & Targeted Value & Para. Value \\
\hline$\mu$ & Literature & 0.6 & 0.6 \\
$\theta_{a}$ & $90-10$ earning ratio & 5.0 & 7.8 \\
$\gamma$ & between-job inequality & 0.04 & 0.42 \\
$b$ & minimum effort level & 1 & 0.16 \\
$\left\{M_{j}\right\}$ & fraction of workers at each job & Figure A.5 & \\
$\left\{p_{j}\right\}$ & job relatedness & Figure 6 & \\
$\left\{\alpha_{j}\right\}$ & performance-pay incidence & Figure 8 & \\
$\left\{A_{j}\right\}$ & average earning at each job over the overall mean & Figure A.5 & \\
$\left\{\theta_{s j}\right\}$ & within-job inequality & Figure 8 & \\
\hline
\end{tabular}

Of course, due to strict parameter restriction, ${ }^{16}$ it is impossible to exactly match the data counterparts. Nonetheless, the model is still capable of matching the key features regarding to the inequality patterns and performance-pay incidence at each job. To see this, we plot in the left panel of Figure 8 within-job inequality in the data versus the model, and in the right panel performance-pay incidence in the data versus the model. It is clear that our model

\footnotetext{
${ }^{15}$ The average pay at job $j$ is defined as: $E_{j}=\frac{N_{j p}}{N_{j}} E_{j p}+\frac{N_{j f}}{N_{j}} w$

${ }^{16}$ For example, $\left\{\alpha_{j}\right\}$ need to be between 0 and 1 and $\gamma$ needs to be smaller than 1 . In addition, $\left\{M_{j}\right\}$ are required to be sorted ascending.
} 
Table 3: Benchmark Results

\begin{tabular}{lrrrr}
\hline & \multicolumn{2}{c}{1990} & \multicolumn{2}{c}{2000} \\
\cline { 2 - 5 } & Data & Model & Data & Model \\
\cline { 2 - 5 } Within-job & 0.164 & 0.199 & 0.231 & 0.240 \\
Between-job & 0.032 & 0.035 & 0.040 & 0.043 \\
Overall & 0.196 & 0.234 & 0.270 & 0.283 \\
\hline
\end{tabular}

Note: Data on each type of inequalities are computed from CPS-March. Model implied patterns on inequalities are based upon calibration.

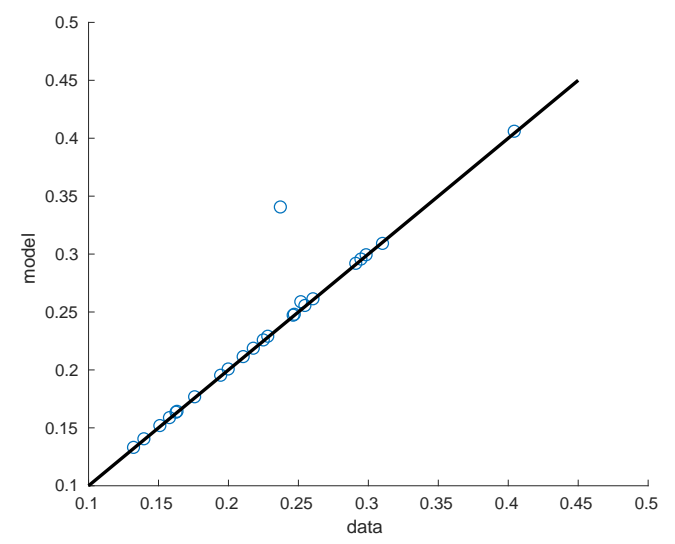

(a) Withi-job Inequality

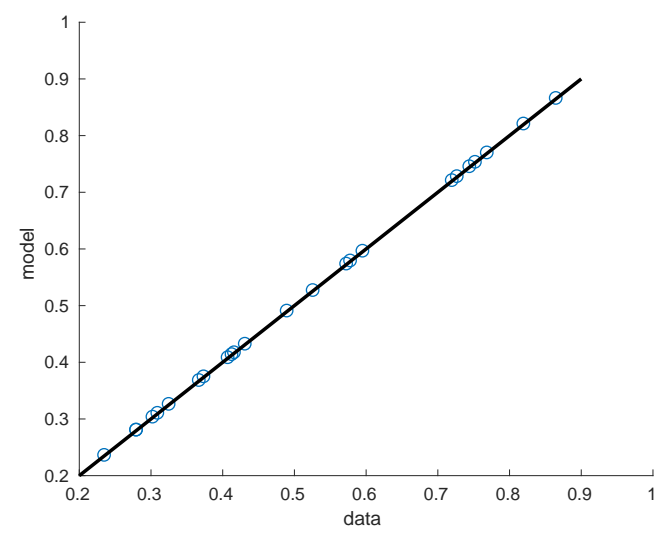

(b) Performance-pay Incidence

Note: On the left panel, each dot represents a job. $\mathrm{x}$-axis is the inequality from data, and $\mathrm{y}$-axis is the inequality computed from model. On the right panel, $x$-axis is performance-pay incidence from data, and y-axis is performance-pay incidence from model.

Figure 8: Model fitness in 2000

fitness in these important measures is quite good.

\subsection{Decompose the changes in within-job inequality}

To further disentangle how performance-pay, job relatedness, sorting as well as job-specific productivities affect the pattern of within-job inequality, we conduct the decomposition analysis in this section. Our exercise is to change the value of each job-specific series in 2000 into their respective values in 1990, while maintaining all other parameters at their benchmark value.

In order to obtain those job-specific series in 1990, we have also re-calibrated the model to year 1990 following identical strategy as the exercise in 2000. Table 3 also compares the aggregate results between the data and model. Similar to the outcome in 2000, the 
model slightly overpredicts both within- and between- job inequality. In Figure 9, we have also plotted the job-specific inequality and performance-pay incidence between the data and model in 1990. We can see that the over-predictions of the 1990 within-job inequality stem primarily from 4 jobs. Overall, the calibrated model still decently mimics the data counterpart.

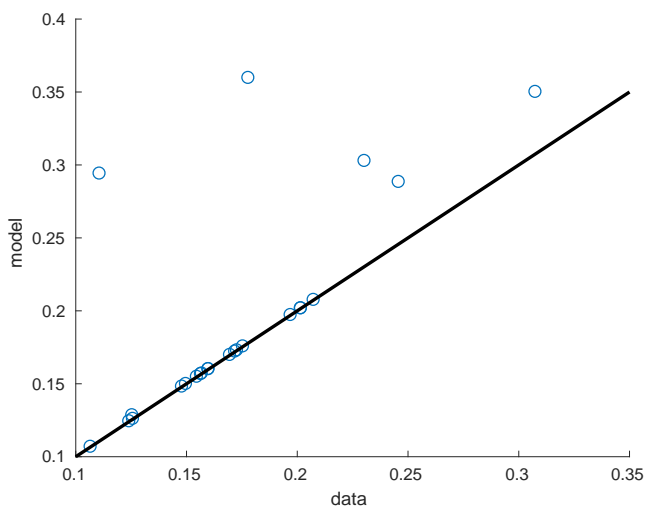

(a) Within-job Inequality

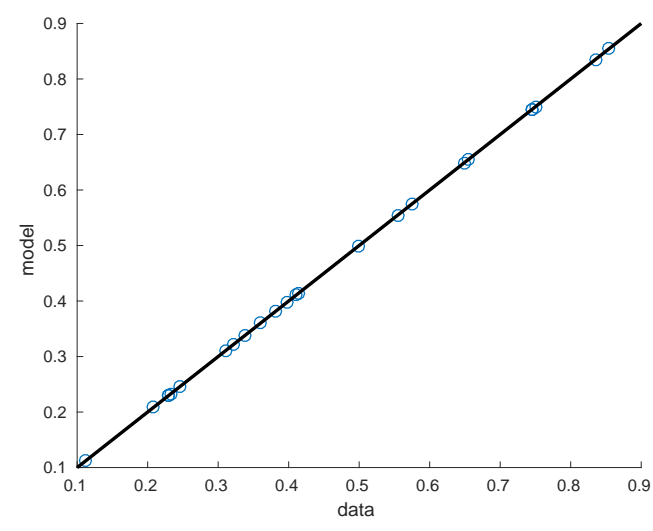

(b) Performance-pay Incidence

Note: On the left panel, each dot represents a job. $\mathrm{x}$-axis is the inequality from data, and $\mathrm{y}$-axis is the inequality computed from model. One the right panel, $\mathrm{x}$-axis is performance-pay incidence from data, and y-axis is performance-pay incidence from model.

Figure 9: Model fitness in 1990

In the benchmark decomposition analysis, we avoid potential problems arising from misfit by focusing on the 20 jobs with good fit, where the correlation between the model predicted within-job inequality and the data counterpart is 0.936 . We leave the analysis for the full sample of 24 jobs to the Appendix B. The main results remain qualitatively similar, despite a few large percentage contribution figures distorted by large residuals.

To evaluate the contribution of factor $s$ to the changes of inequality from 1990 to 2000 at job $j$, denoted as $\pi_{s}^{j}$, we apply the following formula:

$$
\pi_{s}^{j}=\frac{\left(\text { model }_{2000}^{j}-\text { counter }_{s}\right)^{j}}{\sum_{s^{\prime}}\left(\text { model }_{2000}^{j}-\text { counter }_{s^{\prime}}{ }^{\prime}\right)}\left(\frac{\text { model }_{2000}^{j}-\text { model }_{1990}^{j}}{\operatorname{data}_{2000}^{j}-\text { data }_{1990}^{j}}\right)
$$

where $\operatorname{model}_{1990}^{j}$ and model $_{2000}^{j}$ denote the model predicted inequality in 1990 and 2000 at job $j$, respectively. data $a_{1990}^{j}$ and $d a t a_{2000}^{j}$ in turn denote the inequality in the data over the two years. counter ${ }_{s}^{j}$ is the inequality obtained from the counterfactual economy, in which we 
move the job-specific factor $s$ from their values in 2000 to those in 1990 .

In total, we have evaluated 4 contributing factors from the model: performance-pay incidence, job relatedness, job-specific productivity, and sorting-induced changes in employment shares. The fraction that cannot be accounted by the model is due to "residuals" arising from missing factors, which is small in the benchmark with 20 jobs. Specifically, the contribution of residual is expressed as:

$$
\pi_{r e s}^{j}=1-\left(\frac{\text { model }_{2000}^{j}-\text { model }_{1990}^{j}}{\operatorname{data}_{2000}^{j}-\operatorname{data}_{1990}^{j}}\right)
$$

Finally, the overall contribution of factor $s$, denoted as $\bar{\pi}_{s}$, is an average of its contribution at each job weighted by the employment share of each job:

$$
\bar{\pi}_{s}=\frac{\sum_{j} \pi_{s}^{j} N_{j}}{\sum_{k} \sum_{j} \pi_{k}^{j} N_{j}}
$$

where $N_{j}$ is the employment share in job $j$.

Table 4: The Contribution of Each Channel

\begin{tabular}{lcccccc}
\hline Channel & Performance & Relatedness & Productivity & Sorting & Residual & Total \\
\hline Contribution & $41.75 \%$ & $25.54 \%$ & $26.03 \%$ & $-1.33 \%$ & $8.01 \%$ & $100.00 \%$ \\
\hline
\end{tabular}

Note: The result for each channel is computed as average across jobs weighted by employment share.

In Table 4, we have reported the overall contribution of each channel. The contribution of performance-pay incidence, job relatedness, job-specific productivity and sorting is $41.75 \%, 25.54 \%, 26.03 \%$ and $-1.33 \%$, respectively. Thus, the model can capture around 92\% of the changes in within-job wage inequality from 1990 to 2000, among which the rising performance-pay incidence and the reducing job relatedness alone can account for more than two-third of the widening wage dispersion.

To gain further insight, we proceed with additional decomposition analyses by different grouping, by industry or occupation, and by changes in ranking of job earnings or employment shares from 1990 to 2000. We will focus on those with large deviations in group outcomes from the overall aggregate outcomes. 
To examine the contribution of each factor at the industry level, we aggregate its contribution at the job level into the industry level adjusted by the employment share:

$$
\bar{\pi}_{s}^{i}=\frac{\sum_{j \in i} \pi_{s}^{j} N_{j}}{\sum_{j \in i} N_{j}},
$$

where $i$ is the industry index and $j$ denotes the job index that belongs to industry $i$. Table 5 presents the results. We find that performance-pay incidence becomes much more important in business/professional service industry contributing more than 3 quarters of the change in within-job inequality. On the contrary, its role is negligible in personal service/trade industry. While job relatedness is crucial for wage dispersion in mining/goods/construction industry contributing almost half, it is far less influential in business/professional service. Furthermore, job-specific productivity plays an essential role in personal service/trade industry contributing almost half, it is inconsequential to business/professional service industry. Throughout all industries, sorting is never important. Most interestingly, the widening wage inequality in business/professional service industry is largely driven by performance-pay incidence only in which none of the other factors contribute more than $10 \%$.

Table 5: Decomposition by industries

\begin{tabular}{|c|c|c|c|c|c|}
\hline Industry & Performance & Relatedness & Productivity & Sorting & Residual \\
\hline mining, durables/non-durables, construction & 0.316 & 0.491 & 0.402 & 0.048 & -0.257 \\
\hline transportation and utility & 0.539 & 0.125 & 0.397 & -0.056 & -0.006 \\
\hline FIRE & 0.125 & 0.272 & 0.315 & 0.053 & 0.235 \\
\hline business, professional service & 0.765 & 0.070 & -0.025 & -0.086 & 0.275 \\
\hline personal service, whole/retail trade & 0.014 & 0.249 & 0.476 & -0.004 & 0.265 \\
\hline Aggregate & 0.418 & 0.255 & 0.260 & -0.013 & 0.080 \\
\hline
\end{tabular}

Note: The result for each industry is weighted sum across occupations within the industry.

Similarly, we can compute the contribution of each factor at the occupation level by aggregating its contribution at the job level into the occupation level adjusted by the employment share. As shown in Table 6, performance-pay incidence turns out to be the only influential channel in the professional occupation contributing almost three quarters, but plays little role in sales occupation. Somewhat surprisingly, in manager occupation, its contribution is only one-sixth, much lower than the overall contribution. This may be due to the well-known agency problem. In sales occupation, the contribution of job relatedness 
and the productivity are much higher than the overall outcome, while they contribute little in professional occupation. Job-specific productivity also contribute much more than the overall in craftsmen/operative/labor and clerical occupations. Throughout all occupations, sorting is never important, which contrasts the occupational demand effect emphasized in the literature (e.g., see Burstein, Morales and Vogel (2019)).

Table 6: Decomposition by occupations

\begin{tabular}{lccccc}
\hline Occupation & Performance & Relatedness & Productivity & Sorting & Residual \\
\hline Professional & 0.724 & 0.043 & -0.042 & -0.032 & 0.307 \\
manager & 0.166 & 0.425 & 0.229 & 0.060 & 0.119 \\
sales & 0.056 & 0.767 & 0.881 & 0.033 & -0.736 \\
craftsmen,operative,labor & 0.132 & 0.332 & 0.587 & -0.046 & -0.004 \\
Clerical,service & 0.185 & 0.226 & 0.678 & -0.095 & 0.006 \\
Aggregate & 0.418 & 0.255 & 0.260 & -0.013 & 0.080 \\
\hline
\end{tabular}

Note: The result for each occupation is weighted sum across industries within the occupation.

In the benchmark economy, jobs are sorted by average wages. From 1990 to 2000 the ranking of jobs may change. In our exercise, ranking at the first slot implies the job has the lowest average wage among all the jobs. In the following analysis, we group jobs with similar changes in ranking to examine how the role of each channel may vary over different categories. If the job's job bin rises, then this job stands at a higher ranking in 2000 than in 1990 and thus there are more jobs with lower average wage than this job in 2000 than in 1990. We can also group by ranking of each job's employment share also changed from 1990 to 2000 with ranking at the first being one having the lowest employment share. We group the jobs with similar changes in ranking. If the job's employment bin rises, then there are more jobs with lower employment share than the specific job in 2000 than in 1990. Table 7 and Table 8 present the results grouped by job bin and employment bin changes, respectively. We find performance-pay incidence playing the greatest role in jobs with stable ranking in either job bin or employment bin. While job relatedness is most crucial for jobs dropped in ranking, job-specific productivity is most important for jobs rising in ranking.

The ranking of within-job inequality also changed from 1990 to 2000. Ranking at the first slot implies the job has the lowest inequality among all the jobs. We group the jobs by similar changes in their rankings and conduct the exercise in Table 9. If the job's inequality bin rises, this implies the specific job rank higher in 2000 than in 1990 and thus there are 
Table 7: Decomposition by job bin change

\begin{tabular}{lccccc}
\hline Job bin & Performance & Relatedness & Productivity & Sorting & Residual \\
\hline Drop by 3 or more & 0.143 & 0.228 & 0.316 & 0.070 & 0.243 \\
Drop by 1 or 2 & 0.274 & 0.459 & 0.427 & 0.050 & -0.210 \\
Stay & 0.674 & 0.084 & 0.008 & -0.083 & 0.316 \\
Rise by 1 or 2 & 0.223 & 0.232 & 0.585 & -0.046 & 0.007 \\
Rise by 3 or more & 0.071 & 0.435 & 0.540 & -0.040 & -0.005 \\
Aggregate & 0.418 & 0.255 & 0.260 & -0.013 & 0.080 \\
\hline
\end{tabular}

Note: In the column of "Job bin ", jobs are grouped with similar change of the ranks of average wage.

Table 8: Decomposition by employment bin change

\begin{tabular}{lccccc}
\hline Emp. bin & Performance & Relatedness & Productivity & Sorting & Residual \\
\hline Rise & 0.159 & 0.196 & 0.516 & 0.011 & 0.118 \\
Stay & 0.525 & 0.143 & 0.124 & -0.048 & 0.256 \\
Drop & 0.321 & 0.474 & 0.409 & 0.038 & -0.241 \\
Aggregate & 0.418 & 0.255 & 0.260 & -0.013 & 0.080 \\
\hline
\end{tabular}

Note: In the column of "Emp. bin", jobs are grouped with similar change of the ranks of employment share.

more jobs with lower equality than the specific job in 2000 than that in 1990. We find that performance-pay channel is most important for jobs with relatively stable wage dispersion ranking. For jobs dropped in ranking with much less dispersed wages, both job relatedness and job-specific productivity become key drivers of changes in inequality. For jobs rising in ranking with much more dispersed wages, the relative importance of performance-pay, relatedness and productivity channels turns out to be similar to the overall outcomes.

Table 9: Decomposition by inequality bin change

\begin{tabular}{lccccc}
\hline Inequality & Performance & Relatedness & Productivity & Sorting & Residual \\
\hline Rise by 2 more & 0.361 & 0.222 & 0.265 & 0.020 & 0.132 \\
Rise by 1 or stay or drop by 1 & 0.540 & 0.122 & 0.052 & -0.044 & 0.330 \\
Drop by 2 or more & 0.138 & 0.851 & 1.021 & -0.005 & -1.006 \\
Aggregate & 0.418 & 0.255 & 0.260 & -0.013 & 0.080 \\
\hline
\end{tabular}

Note: In the column of "inequality", jobs are grouped with similar change of the ranks of inequality.

Finally, we select 6 jobs based on their characteristics on earning and employment share to perform the decomposition exercise. Table 10 shows that performance-pay incidence contributes greatly to widening wage dispersion in the business-professional pair, While job 
relatedness is crucial in the transportation-sales pair, job-specific productivity is particularly important in the goods-clerical pair. Of particular interest, sorting turns out to be highly relevant in the FIRE-manager pair, accounting for about $15 \%$ of the rising within-job wage inequality.

Table 10: Decomposition by selected jobs

\begin{tabular}{lccccc}
\hline job & Performance & Relatedness & Productivity & Sorting & Residual \\
\hline business, production & 0.071 & 0.435 & 0.540 & -0.040 & -0.005 \\
transp, sales & 0.279 & 0.696 & 0.008 & 0.036 & -0.019 \\
trade, sales & 0.000 & 0.223 & 0.412 & -0.040 & 0.405 \\
business, professional & 0.855 & 0.044 & -0.126 & -0.092 & 0.319 \\
FIRE, manager & 0.080 & 0.326 & 0.241 & 0.154 & 0.200 \\
goods, clerical & 0.336 & 0.033 & 0.744 & -0.117 & 0.003 \\
\hline
\end{tabular}

Note: In the column of "job", jobs are defined by industry-occupation pairs.

\subsection{Discussion: job relatedness on multiple dimension skills}

One may inquiry whether our findings are robust to inclusion of multiple dimensions of skills. Specifically, workers' skills are in multiple dimensions, and jobs have different requirements on different dimensions. In this case, there is no simple way to rank people by skills. People with high skills in some dimensions may have low ones in other dimensions. Hence as job becomes more specialized in skill types, wage inequality may change as well.

We model the job relatedness in the world of multiple dimension skills. Worker's skills have $\mathrm{N}$ dimensions $a=\left(a_{1}, \cdots, a_{N}\right)$, and job $g$ has skill requirement on $N_{g}(\leq N)$ dimensions. Let $N_{g}$ also the set of abilities effective in job $g$, and the effective labor in job $g$ is $g=$ $\left\{g_{k} \mid k \in N_{g}\right\}$. Let time allocations are $\left(l_{k}\right)_{k \in N_{g}}$, and assume effort level is 1 for every one, then the effective labor in an unit time is $h(a, g)=A_{g}\left[\sum_{k \in N_{g}}\left(a_{k} g_{k} l_{k}\right)^{\frac{\epsilon-1}{\epsilon}}\right]^{\frac{\epsilon}{\epsilon-1}}$, where $\epsilon$ is the elasticity of substitution between abilities in different dimensions. The optimal time allocation implies that $h(a, g)=A_{g}\left[\sum_{k \in N_{g}}\left(a_{k} g_{k}\right)^{\epsilon-1}\right]^{\frac{1}{\epsilon-1}}$. If there is only one dimension in both the skill and the requirement, then $h(a, g)=A_{g} a g$, which is exactly the same as that in benchmark model. If there is only one type of skill but multiple job requirements then $h(a, g)=A_{g} a\left[\sum_{k \in N_{g}}\left(g_{k}\right)^{\epsilon-1}\right]^{\frac{1}{\epsilon-1}}$, and $\eta=\left[\sum_{k \in N_{g}}\left(g_{k}\right)^{\epsilon-1}\right]^{\frac{1}{\epsilon-1}}$ is the productivity premium adjusted by the optimal time allocation. Therefore, in this case, given data availability it 
is possible to have a more accurate measurement on productivity premium, but in terms of contribution to wage inequality, it would be similar to the benchmark.

\section{Conclusion}

In this paper, we have documented that within-job inequality greatly contributes to residual wage inequality. To explain this fact, we have developed a model in which within-job wage inequality is influenced by both performance-pay incidence and job relatedness. Workers with higher abilities are sorted into performance-pay positions across jobs. The overall relationship between job relatedness and within-job wage inequality is generally ambiguous. The main quantitative results suggest that the model accounts for around $92 \%$ of within-job wage inequality increase among the highly educated from 1990 to 2000. Job relatedness explains $42 \%$ and performance-pay position explains $26 \%$. In addition, the decomposition exercise reveals that the role of each channel may vary substantially over different categories of jobs. The paper has shed light on the main source of residual wage inequality within jobs. While performance-pay or job-specific productivity induced wage inequality is seen natural, the inequality driven by reduction in the relatedness between the college graduates' major and their jobs may deserve policy attention.

The model could be extended to discuss the underlying reasons for job relatedness. In particular, a worker in an unrelated job may do so because of search friction, or the rising role of multi-tasking, or the trade-off between personal interests and earnings. By incorporating these underlying reasons, the model could generate richer policy implications. The model could also be extended to include multiple dimension skills to study the effects of job specialization wage inequality, where job specialization is modeled as the decline in the dimensions of skill requirement. Arguably, a worker who fits the job well will have higher wage increase than those less fitted, but one with the highly specialized skill may become a loser in re-sorting. Within-job wage inequality may change as the degree of specialization changes over different types of jobs. 


\section{References}

Acemoglu, Daron. 2003. "Patterns of skill premia." The Review of Economic Studies 70(2):199-230.

Acemoglu, Daron and David Autor. 2011. "Skills, tasks and technologies: Implications for employment and earnings." Handbook of Labor Economics 4:1043-1171.

Altonji, Joseph G, Lisa B Kahn and Jamin D Speer. 2014. "Trends in Earnings Differentials across College Majors and the Changing Task Composition of Jobs." The American Economic Review: Papers \& Proceedings 104(5):387-393.

Altonji, Joseph G, Lisa B Kahn and Jamin D Speer. 2016. "Cashier or consultant? Entry labor market conditions, field of study, and career success." Journal of Labor Economics 34(S1):S361-S401.

Arcidiacono, Peter. 2004. "Ability sorting and the returns to college major." Journal of Econometrics 121(1):343-375.

Autor, David H, Lawrence F Katz and Melissa S Kearney. 2008. "Trends in US wage inequality: Revising the revisionists." The Review of Economics and Statistics 90(2):300-323.

Barth, Erling, Alex Bryson, James C Davis and Richard Freeman. 2011. "The contribution of dispersion across plants to the increase in US earnings dispersion.".

Beaudry, Paul and David A Green. 2005. "Changes in US Wages, 1976-2000: Ongoing Skill Bias or Major Technological Change?" Journal of Labor Economics 23(3):609-648.

Beaudry, Paul, David A Green and Benjamin M Sand. 2014. "The declining fortunes of the young since 2000." The American Economic Review: Papers $\&$ Proceedings 104(5):381386.

Burstein, Ariel, Eduardo Morales and Jonathan Vogel. 2019. "Changes in Between-Group Inequality: Computers, Occupations, and International Trade." American Economic Journal: Macroeconomics 11(2):348-400. 
Card, David and John E DiNardo. 2002. "Skill-biased technological change and rising wage inequality: Some problems and puzzles." Journal of Labor Economics 20(4):733-783.

Card, David, Jörg Heining and Patrick Kline. 2013. "Workplace Heterogeneity and the Rise of West German Wage Inequality." The Quarterly Journal of Economics 128(3):967-1015.

Dorn, David. 2009. Essays on inequality, spatial interaction, and the demand for skills PhD thesis Verlag nicht ermittelbar.

Galor, Oded and Omer Moav. 2000. "Ability-biased technological transition, wage inequality, and economic growth." The Quarterly Journal of Economics pp. 469-497.

Guvenen, Fatih, Burhan Kuruscu, Satoshi Tanaka and David Wiczer. 2020. "Multidimensional Skill Mismatch." American Economic Journal: Macroeconomics 12(1):210-44.

Guvenen, Fatih, Burhanettin Kuruscu, Satoshi Tanaka and David Wiczer. 2015. "Multidimensional Skill Mismatch.".

Heywood, John S and Daniel Parent. 2012. "Performance pay and the white-black wage gap." Journal of Labor Economics 30(2):249-290.

Jensen, Michael C and Kevin J Murphy. 1990. "Performance pay and top-management incentives." Journal of Political Economy 98(2):225-264.

Jovanovic, Boyan. 2014. "Misallocation and Growth." The American Economic Review 104(4):1149-1171.

Juhn, Chinhui, Kevin M Murphy and Brooks Pierce. 1993. "Wage inequality and the rise in returns to skill." Journal of Political Economy 101(3):410-442.

Kambourov, Gueorgui and Iourii Manovskii. 2009. "Occupational mobility and wage inequality." The Review of Economic Studies 76(2):731-759.

Katz, Lawrence F and David H. Autor. 1999. "Changes in the wage structure and earnings inequality." Handbook of Labor Economics 3:1463-1555. 
Kirkeboen, Lars J, Edwin Leuven and Magne Mogstad. 2016. "Field of study, earnings, and self-selection." The Quarterly Journal of Economics 131(3):1057-1111.

Krusell, Per, Lee E Ohanian, José-Víctor Ríos-Rull and Giovanni L Violante. 2000. "Capital-skill complementarity and inequality: A macroeconomic analysis." Econometrica 68(5):1029-1053.

Lazear, Edward P. 2000. "Performance Pay and Productivity." The American Economic Review 90(5):1346-1361.

Lee, Sang Yoon, Yongseok Shin and Donghoon Lee. 2015. The option value of human capital: Higher education and wage inequality. Technical report National Bureau of Economic Research.

Lemieux, Thomas. 2006. "Increasing residual wage inequality: Composition effects, noisy data, or rising demand for skill?" The American Economic Review 96(3):461-498.

Lemieux, Thomas, W Bentley MacLeod and Daniel Parent. 2009. "Performance Pay and Wage Inequality." The Quarterly Journal of Economics 124(1):1-49.

Leuven, Edwin and Hessel Oosterbeek. 2011. "Overeducation and mismatch in the labor market." Handbook of the Economics of Education 4:283-326.

Lise, Jeremy and Fabien Postel-Vinay. 2015. "Multidimensional Skills, Sorting, and Human Capital Accumulation.".

Mueller, Holger M, Paige P Ouimet and Elena Simintzi. 2017. "Wage inequality and firm growth." American Economic Review 107(5):379-83.

Papageorgiou, Theodore. 2010. "Large Firms and Internal Labor Markets." Working paper.

Piketty, Thomas and Emmanuel Saez. 2003. "Income Inequality in the United States, 19131998." The Quarterly Journal of Economics 118(1):1-39.

Piketty, Thomas and Emmanuel Saez. 2014. "Inequality in the long run." Science $344(6186): 838-843$. 
Ritter, Joseph A. and Kristine L. West. 2014. "Field of Study and Earnings Inequality among the Highly Educated: 1993-2010." Working paper.

Robst, John. 2007. "Education and job match: The relatedness of college major and work." Economics of Education Review 26(4):397-407.

Sanders, Carl. 2014. "Skill Uncertainty, Skill Accumulation, and Occupational Choice." Working Paper.

Scotese, Carol A. 2012. "Wage inequality, tasks and occupations." Working Paper.

Shi, Shouyong. 2002. "A directed search model of inequality with heterogeneous skills and skill-biased technology." The Review of Economic Studies 69(2):467-491.

Song, Jae, David J Price, Fatih Guvenen, Nicholas Bloom and Till Von Wachter. 2018. "Firming up inequality." The Quarterly Journal of Economics 134(1):1-50.

Violante, Giovanni L. 2002. "Technological acceleration, skill transferability, and the rise in residual inequality." The Quarterly Journal of Economics 117(1):297-338. 


\section{Appendix}

(Not Intended for Publication)

\section{A Tables and Figures}

\section{A.1 Wage inequality}

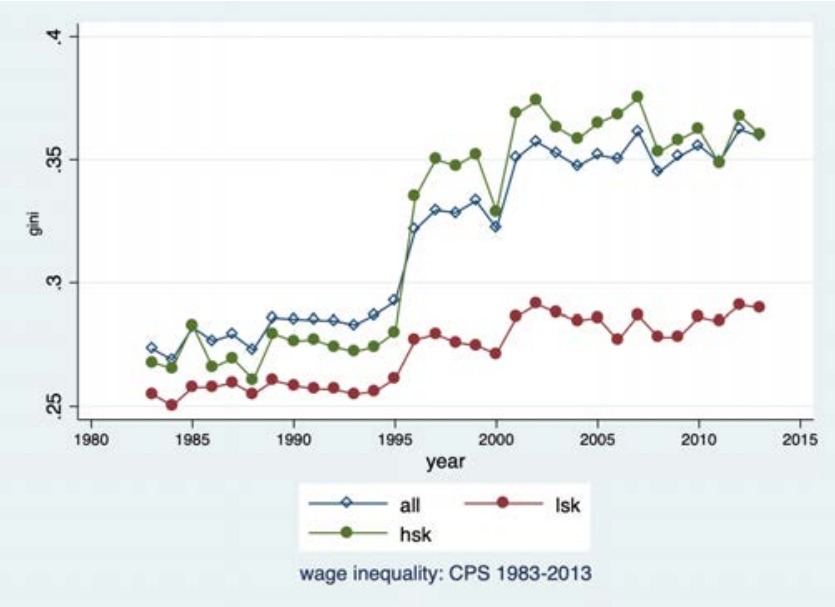

(a) Gini Coefficient

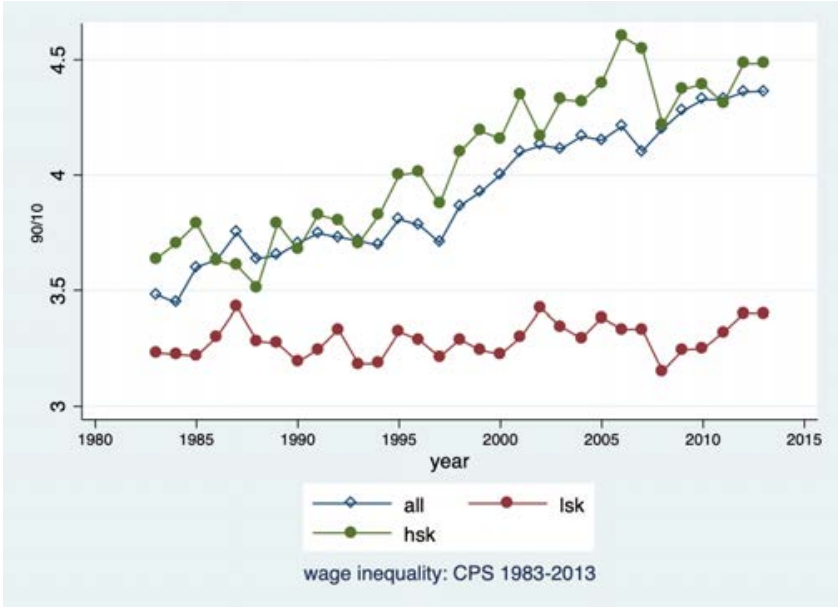

(b) 90-10 Percentile Ratio

Figure A.1: Wage inequality: Gini and 90-10 percentile ratio

Source: March CPS from CEPR. 


\section{A.2 Performance pay incidence}

Lemieux, MacLeod and Parent (2009) estimate performance-pay incidence for all the workers, and Table A.1 presents their results.

Table A.1: Incidence of performance-pay jobs: PSID 1976-1998

\begin{tabular}{|l|l|l|l|l|l|l|l|l|l|}
\hline & Professionals & Managers & Sales & Clerical & Craftsmen & Operatives & Laborers & Services & Total \\
\hline Min.\&durables & 0.46 & 0.60 & 0.74 & 0.35 & 0.21 & 0.26 & 0.26 & 0.19 & 0.33 \\
Nondurables & 0.52 & 0.62 & 0.79 & 0.38 & 0.26 & 0.42 & 0.25 & 0.06 & 0.43 \\
Transport\&utils. & 0.23 & 0.52 & 0.82 & 0.28 & 0.27 & 0.37 & 0.44 & 0.37 & 0.35 \\
Fin.insur.,\&real est. & 0.75 & 0.72 & 0.87 & 0.38 & 0.29 & 0.04 & 0.22 & 0.33 & 0.65 \\
Bus.\&prof.serv & 0.41 & 0.57 & 0.73 & 0.39 & 0.46 & 0.40 & 0.18 & 0.25 & 0.43 \\
Personal serv. & 0.42 & 0.63 & 0.61 & 0.24 & 0.33 & 0.20 & 0.29 & 0.49 & 0.46 \\
Whol-tr.\&oth serv. & 0.65 & 0.66 & 0.82 & 0.45 & 0.29 & 0.46 & 0.29 & 0.03 & 0.58 \\
Retail trade & 0.27 & 0.57 & 0.72 & 0.33 & 0.48 & 0.32 & 0.21 & 0.46 & 0.50 \\
Construction & 0.72 & 0.47 & 0.81 & 0.20 & 0.33 & 0.30 & 0.30 & 0.17 & 0.36 \\
Agriculture\&fishing & 0.72 & 0.78 & 0.88 & 0.24 & 0.16 & 0.42 & 0.45 & 0.77 & 0.46 \\
\hline Total & 0.45 & 0.59 & 0.78 & 0.34 & 0.30 & 0.33 & 0.31 & 0.34 & 0.42 \\
\hline
\end{tabular}

Notes:Lemieux, MacLeod and Parent (2009).

\section{A.3 Skill mismatch}

\section{A.3.1 Negative wage effect of skill mismatch}

As shown in Guvenen et al. (2015), there is a negative wage effect of skill mismatch.

Table A.2: Wage Losses from Mismatch

\begin{tabular}{cccc}
\hline Mismatch Degree & \multicolumn{3}{c}{ Mismatch effect } \\
\hline \hline (High to Low $)$ & 5 years & 10 years & 15 years \\
\hline $90 \%$ & -0.052 & -0.088 & -0.124 \\
\hline $70 \%$ & -0.034 & -0.057 & -0.080 \\
\hline $50 \%$ & -0.023 & -0.039 & -0.054 \\
\hline $30 \%$ & -0.015 & -0.026 & -0.036 \\
\hline $10 \%$ & -0.008 & -0.014 & -0.020 \\
\hline
\end{tabular}

Source: Guvenen et al. (2015) 


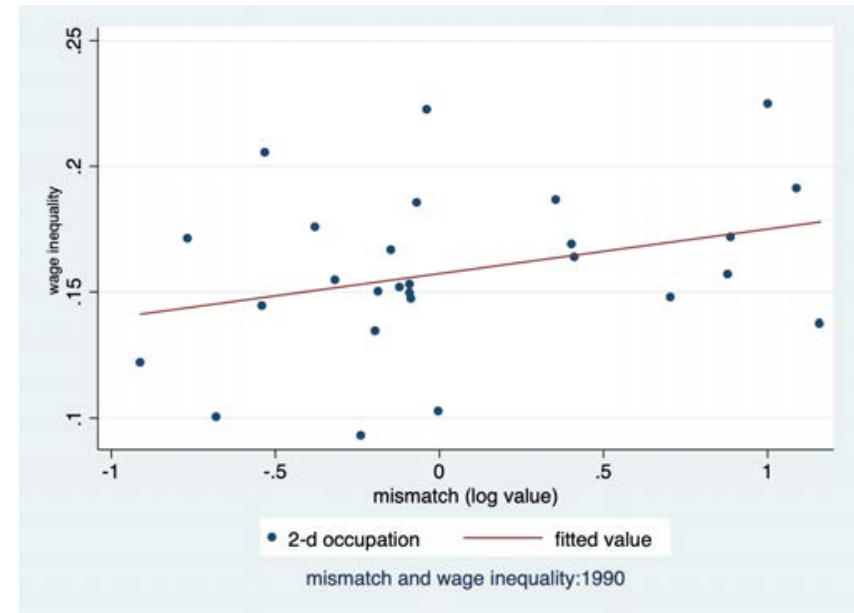

(a) 1990

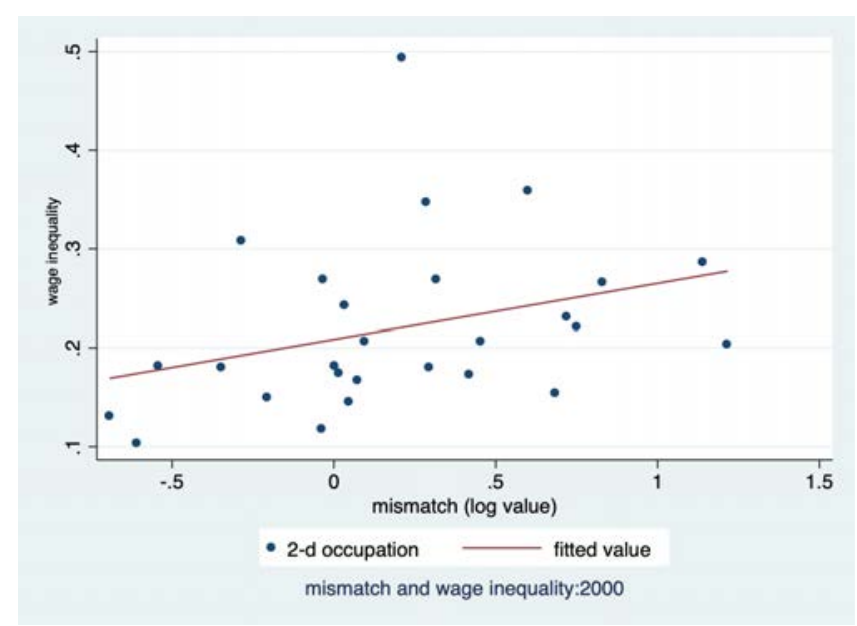

(b) 2000

Figure A.2: Skill mismatch and wage inequality

Source: O*NET and NLSY79. The upper panel is based on 1990 data, and lower panel is based on 2000 data. Each dot represents an occupation under 2-digit code, y-axis is the inequality within each occupation, $\mathrm{x}$-axis the $\log$ value of skill mismatch.

\section{A.3.2 Skill mismatch from O*NET and NLSY79}

O*NET has scores of importance of skills (skill requirement) for each occupation: $S_{j}^{R}$, $j=1 \cdots J$. We compute weighted mean of scores as $E S^{R}=\sum \alpha_{j} S_{j}^{R}$, given the standard deviation $\delta_{S^{R}}$, we measure the deviation from mean as $s_{j}^{R}=\frac{S_{j}^{R}-E S^{R}}{\delta_{S^{R}}}$. In addition, NLSY79 has scores of skills for individuals: $S_{i j}^{A}$; $S_{j}^{A}=\sum \alpha_{i j} S_{i j}^{A}$. We also compute the weighted mean as $E S^{A}=\sum \alpha_{j} S_{j}^{A}$, given standard deviation $\delta_{S^{A}}$, the deviation from the mean is $s_{j}^{A}=\frac{S_{j}^{A}-E S^{A}}{\delta_{S A}}$. Then the skill mismatch is the distance between skill requirement and ac- 
quirement $\theta_{s j}=d\left(s_{j}^{R}, s_{j}^{A}\right)$. Based on this measurement, there is also a positive correlation between mismatch and wage inequality.

\section{A.4 Job relatedness}

Table A.3: Statistic description: NSCG1993

\begin{tabular}{ccccccc}
\hline \multirow{2}{*}{ gender } & & observations & tenure & earning & inequality & proportion \\
\hline \multirow{5}{*}{ education } & Female & 34467 & 18.17 & 53814.12 & 0.20 & 0.37 \\
& male & 59893 & 19.73 & 76401.97 & 0.25 & 0.63 \\
\hline \multirow{4}{*}{ race } & Master & 25757 & 20.17 & 68416.25 & 0.20 & 0.27 \\
& PhD & 10540 & 18.68 & 104475.17 & 0.28 & 0.11 \\
& White & 79175 & 19.16 & 68444.02 & 0.23 & 0.84 \\
& Black & 9478 & 19.20 & 55785.14 & 0.19 & 0.10 \\
& Hispanic & 5707 & 17.27 & 62247.22 & 0.20 & 0.06 \\
\hline \multirow{2}{*}{ relatedness } & Close & 55613 & 18.96 & 70803.82 & 0.21 & 0.59 \\
& Some & 24066 & 19.04 & 67695.83 & 0.24 & 0.26 \\
& Not & 14681 & 19.69 & 57021.46 & 0.28 & 0.16 \\
\hline \multirow{2}{*}{ all sample } & & 94360 & 19.11 & 67514.19 & 0.23 & 1 \\
\hline
\end{tabular}


Table A.4: Statistic description: NSCG2003

\begin{tabular}{ccccccc}
\hline \multirow{2}{*}{ gender } & & observations & tenure & earning & inequality & proportion \\
\hline \multirow{5}{*}{ education } & male & 21180 & 20.13 & 60732.11 & 0.28 & 0.38 \\
& Bachelor & 31915 & 20.95 & 69964.33 & 0.34 & 0.58 \\
& Master & 16202 & 21.31 & 77226.22 & 0.28 & 0.29 \\
& PhD & 7348 & 19.72 & 131856.72 & 0.45 & 0.13 \\
\hline \multirow{5}{*}{ race } & White & 47212 & 21.07 & 79947.82 & 0.34 & 0.85 \\
& Black & 4411 & 20.70 & 61798.49 & 0.25 & 0.08 \\
& Hispanic & 3842 & 18.50 & 65085.11 & 0.33 & 0.07 \\
\hline \multirow{2}{*}{ relatedness } & Close & 33377 & 20.45 & 83487.92 & 0.30 & 0.60 \\
& Some & 13871 & 21.14 & 77929.15 & 0.34 & 0.25 \\
\hline \multirow{2}{*}{ all sample } & Not & 8217 & 22.05 & 61807.33 & 0.41 & 0.15 \\
\hline
\end{tabular}

Table A.5: Proportion of relatedness: NSCG

\begin{tabular}{lllllllll}
\hline & & \multicolumn{3}{c}{1993} & & \multicolumn{3}{c}{2003} \\
\hline \hline \multirow{2}{*}{ gender } & & close & some & not & close & some & not \\
\hline \multirow{4}{*}{ educationale } & 0.63 & 0.21 & 0.16 & 0.63 & 0.22 & 0.15 \\
& Male & 0.57 & 0.28 & 0.15 & 0.58 & 0.27 & 0.15 \\
\hline \multirow{4}{*}{ race } & Bachelor & 0.50 & 0.30 & 0.20 & 0.50 & 0.30 & 0.20 \\
& Master & 0.68 & 0.23 & 0.09 & 0.68 & 0.23 & 0.09 \\
& PhD & 0.88 & 0.08 & 0.04 & 0.87 & 0.10 & 0.04 \\
\hline \multirow{2}{*}{ all sample } & White & 0.59 & 0.26 & 0.15 & 0.60 & 0.25 & 0.15 \\
& Black & 0.60 & 0.22 & 0.18 & 0.59 & 0.24 & 0.17 \\
& Hispanic & 0.61 & 0.23 & 0.15 & 0.66 & 0.21 & 0.13 \\
\hline & & 0.59 & 0.26 & 0.16 & 0.60 & 0.25 & 0.15 \\
\hline
\end{tabular}


Table A.6: Wage effect of job relatedness: NSCG(1993,2003)

\begin{tabular}{lll}
\hline VARIABLES & 1990 & 2000 \\
\hline \hline closely related & $\mathbf{0 . 1 2 4 * * *}$ & $\mathbf{0 . 2 4 2} * * *$ \\
& $(0.00437)$ & $(0.00791)$ \\
some related & $\mathbf{0 . 0 9 8 5 * * *}$ & $\mathbf{0 . 1 7 7 ^ { * * * }}$ \\
& $(0.00481)$ & $(0.00866)$ \\
age & $0.0128^{* * *}$ & $0.00859^{* * *}$ \\
male & $0.203^{* * *}$ & $0.260^{* * *}$ \\
education level & $0.0762^{* * *}$ & $0.0820^{* * *}$ \\
black & $-0.0850^{* * *}$ & $-0.108^{* * *}$ \\
Constant & $9.133^{* * *}$ & $9.156^{* * *}$ \\
Observations & 92,786 & 55,410 \\
R-squared & 0.249 & 0.165 \\
\hline
\end{tabular}

Standard errors in parentheses;

$$
* * * \mathrm{p}<0.01, * * \mathrm{p}<0.05, * \mathrm{p}<0.1
$$

Source: NSCG(1993,2003). This table only shows part of results of the regression. 


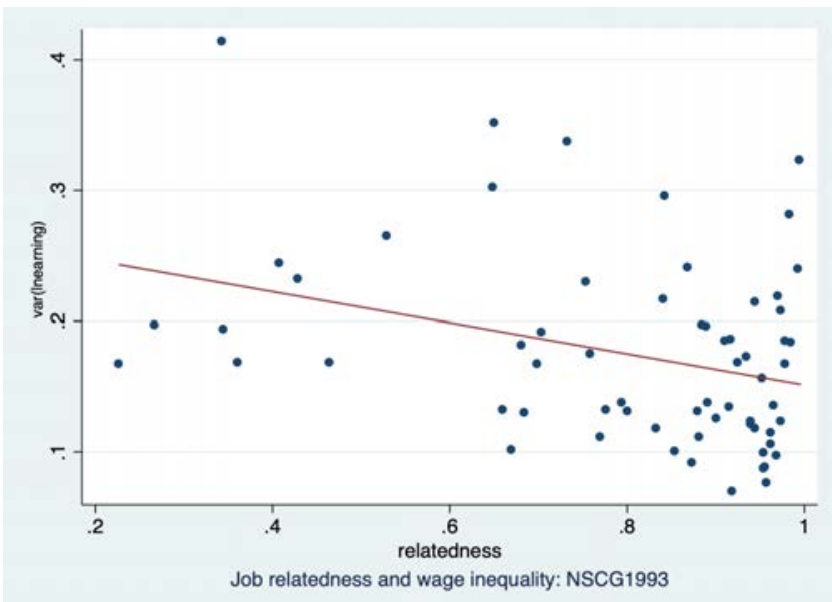

(a) NSCG 1993

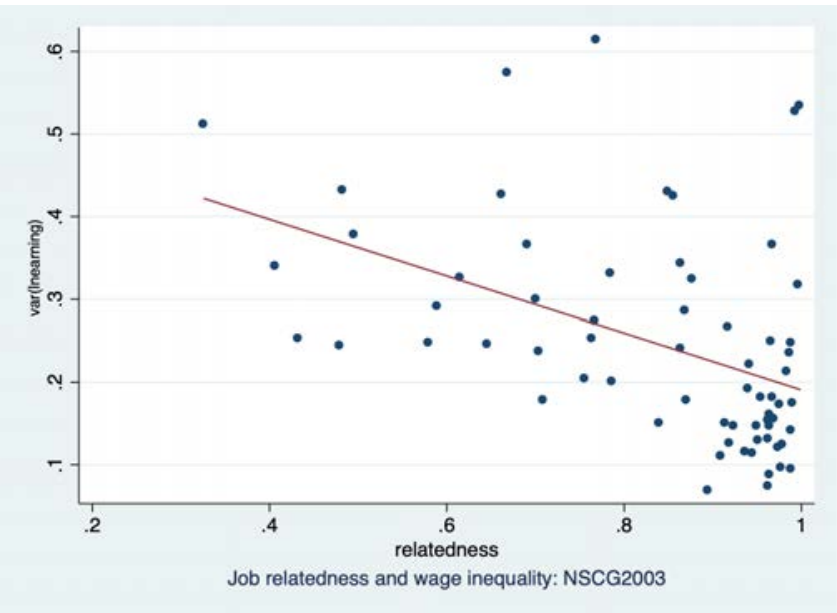

(b) NSCG 2003

Figure A.3: Job relatedness and within-occupation wage inequality

Source: NSCG(1993,2003). The upper panel is based on 1993 data, and lower panel is based on 2003 data. Each dot represents an occupation under 2-digit classfication. y-axis is the inequality within each occupation, $\mathrm{x}$-axis job relatedness. 


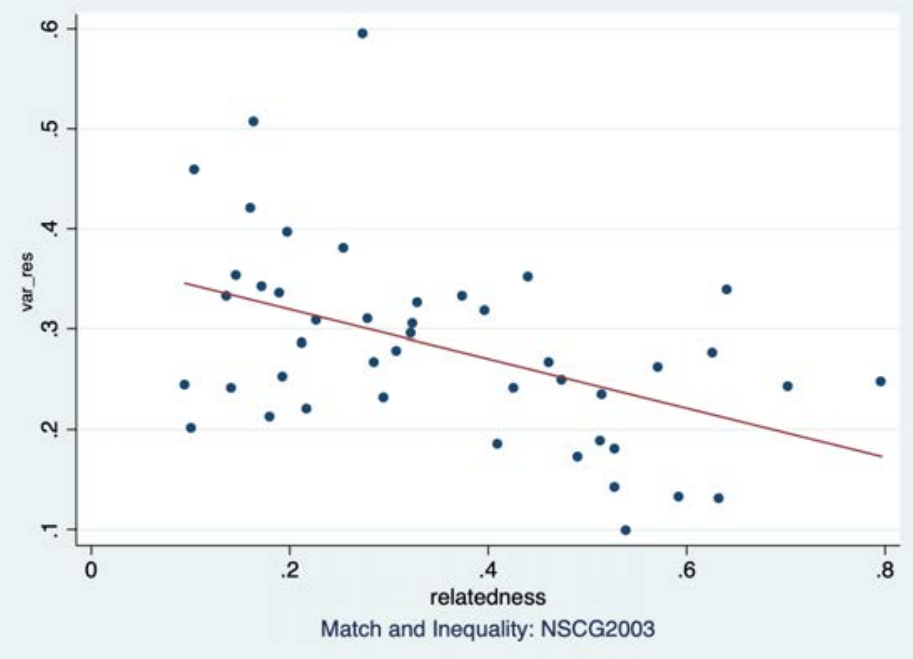

Figure A.4: Job relatedness and within-job wage inequality

Notes: Each dot represents a job. We have extracted 45 jobs from NSCG 2000 dataset after dropping those with observation less than 50. CPS from CEPR. 


\section{A.5 Calibration Targets}

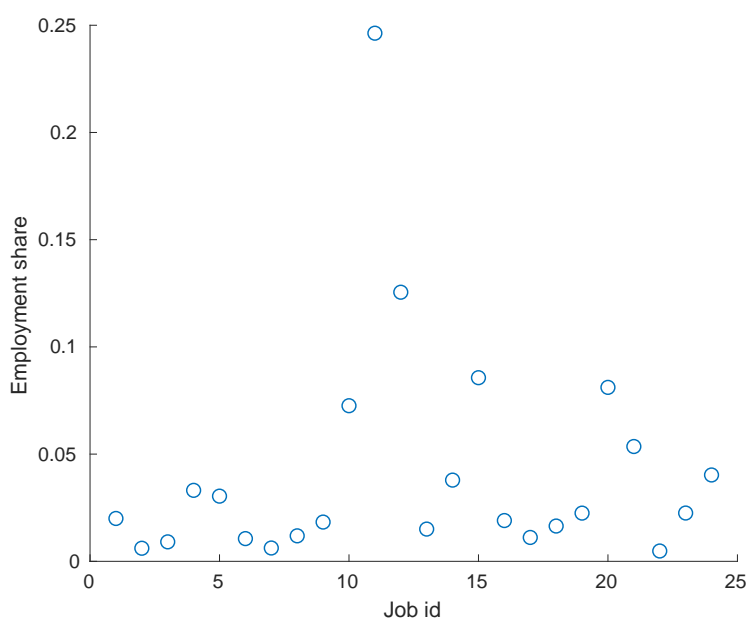

(a) Employment share

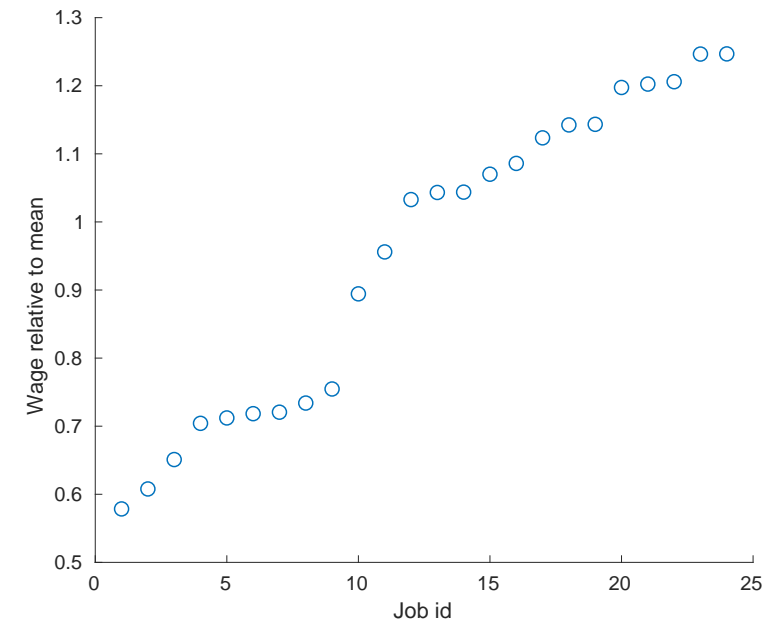

(b) Average wage relative to mean

Figure A.5: Calibration Targets 


\section{B Decomposition analysis for the full sample}

Table B.7: Decomposition by industries

\begin{tabular}{lccccc}
\hline Industry & Performance & Relatedness & Productivity & Sorting & Residual \\
\hline mining, durables/non-durables, construction & 0.316 & 0.491 & 0.402 & 0.048 & -0.257 \\
transportation and utility & 0.539 & 0.125 & 0.397 & -0.056 & -0.006 \\
FIRE & 0.085 & 0.265 & 0.313 & 0.051 & 0.286 \\
business, professional service & 0.338 & -0.157 & -0.003 & -0.058 & 0.880 \\
personal service, whole/retail trade & 0.019 & 0.218 & 0.431 & 0.005 & 0.327 \\
Aggregate & 0.262 & 0.140 & 0.237 & -0.007 & 0.367 \\
\hline
\end{tabular}

Notes: The results are based on 24 jobs. The result for each industry is weighted sum across occupations within the industry.

Table B.8: Decomposition by occupations

\begin{tabular}{lccccc}
\hline Occupation & Performance & Relatedness & Productivity & Sorting & Residual \\
\hline Professional & 0.724 & 0.043 & -0.042 & -0.032 & 0.307 \\
manager & 0.094 & 0.243 & 0.157 & 0.037 & 0.470 \\
sales & -0.466 & 0.043 & 0.703 & 0.039 & 0.682 \\
craftsmen,operative,labor & 0.132 & 0.332 & 0.587 & -0.046 & -0.004 \\
Clerical,service & 0.185 & 0.226 & 0.678 & -0.095 & 0.006 \\
Aggregate & 0.262 & 0.140 & 0.237 & -0.007 & 0.367 \\
\hline
\end{tabular}

Notes: The results are based on 24 jobs. The result for each occupation is weighted sum across industries within the occupation.

Table B.9: Decomposition by job bin change

\begin{tabular}{lccccc}
\hline Job bin & Performance & Relatedness & Productivity & Sorting & Residual \\
\hline Drop by 3 or more & 0.064 & 0.102 & 0.141 & 0.031 & 0.661 \\
Drop by 1 or 2 & 0.274 & 0.459 & 0.427 & 0.050 & -0.210 \\
Stay & 0.674 & 0.084 & 0.008 & -0.083 & 0.316 \\
Rise by 1 or 2 & 0.166 & 0.198 & 0.493 & -0.022 & 0.165 \\
Rise by 3 or more & -1.347 & -1.217 & 0.369 & 0.041 & 3.154 \\
Aggregate & 0.262 & 0.140 & 0.237 & -0.007 & 0.367 \\
\hline
\end{tabular}

Notes: The results are based on 24 jobs. In the column of "job bin change", jobs are grouped with similar change of the ranks of average wage. 
Table B.10: Decomposition by employment bin change

\begin{tabular}{lccccc}
\hline Emp. bin & Performance & Relatedness & Productivity & Sorting & Residual \\
\hline Rise & -0.284 & -0.292 & 0.251 & 0.008 & 1.317 \\
Stay & 0.451 & 0.149 & 0.148 & -0.035 & 0.286 \\
Drop & 0.321 & 0.474 & 0.409 & 0.038 & -0.241 \\
Aggregate & 0.262 & 0.140 & 0.237 & -0.007 & 0.367 \\
\hline
\end{tabular}

Notes: The results are based on 24 jobs. In the column of "employment bin change", jobs are grouped with similar change of the ranks of employment share.

Table B.11: Decomposition by inequality bin change

\begin{tabular}{lccccc}
\hline Inequality & Performance & Relatedness & Productivity & Sorting & Residual \\
\hline Rise by 2 more & 0.230 & 0.169 & 0.212 & 0.019 & 0.369 \\
Rise by 1 or stay or drop by 1 & 0.540 & 0.122 & 0.052 & -0.044 & 0.330 \\
Drop by 2 or more & -0.530 & 0.071 & 0.972 & 0.002 & 0.485 \\
Aggregate & 0.262 & 0.140 & 0.237 & -0.007 & 0.367 \\
\hline
\end{tabular}

Notes: The results are based on 24 jobs. In the column of "employment bin change", jobs are grouped with similar change of the ranks of employment share. 


\section{Proofs}

\section{C.1 Lemma 1}

Proof: worker of ability $a$ chooses to work in job $k$ if $C_{k} a^{2}-M_{k} \geq C_{n} a^{2}-M_{n}, n \neq k$. That is,

$$
\left(C_{k}-C_{n}\right) a^{2} \geq M_{k}-M_{n}, \forall n \neq k
$$

For job $n<k$, we have $C_{k}-C_{n}>0$. It is then straightforward to have the following hold:

$$
\left(C_{k}-C_{n}\right) a^{\prime 2}>\left(C_{k}-C_{n}\right) a^{2} \geq M_{k}-M_{n}, \forall n<k
$$

This implies for workers of ability $a^{\prime}>a$, the utility from working at job $k$ is always higher than working at any job $n<k$. Therefore, workers with ability higher than $a$ will choose to work in job $j \geq k$. Q.E.D.

\section{C.2 Lemma 2}

Proof: Worker prefers job $n$ to $n-1$ if

$$
C_{n} a^{2}-M_{n}>C_{n-1} a^{2}-M_{n-1}
$$

Similarly, worker prefers job $n$ to $n+1$ if

$$
C_{n} a^{2}-M_{n}>C_{n+1} a^{2}-M_{n+1} .
$$

Ability $a$ thus satisfies:

$$
\frac{M_{n+1}-M_{n}}{C_{n+1}-C_{n}}>a^{2}>\frac{M_{n}-M_{n-1}}{C_{n}-C_{n-1}} \text {. Q.E.D. }
$$




\section{C.3 Lemma 3}

Proof: If worker of ability $a$ prefers job $n$ to $n-1$, then

$$
C_{n} a^{2}-M_{n}>C_{n-1} a^{2}-M_{n-1}
$$

The above is equivalent to: $a^{2}>\frac{M_{n}-M_{n-1}}{C_{n}-C_{n-1}}$. When assumption 1 holds, we also have $a^{2}>\frac{M_{n-1}-M_{n-2}}{C_{n-1}-C_{n-2}}$, which is equivalent to:

$$
C_{n-1} a^{2}-M_{n-1}>C_{n-2} a^{2}-M_{n-2}
$$

Therefore, $C_{n} a^{2}-M_{n}>C_{n-2} a^{2}-M_{n-2}$ also holds, and worker thus prefers job $n$ to $n-2$.

By similar induction, it is straightforward to show worker prefers job $n$ to any job $k<$ n-1. Q.E.D.

\section{C.4 Lemma 4}

Proof: If worker of ability $a$ prefers job $n$ to $n+1$, then

$$
C_{n} a^{2}-M_{n}>C_{n+1} a^{2}-M_{n+1}
$$

The above is equivalent to: $a^{2}<\frac{M_{n+1}-M_{n}}{C_{n+1}-C_{n}}$. When assumption 1 holds, we also have $a^{2}<\frac{M_{n+2}-M_{n+1}}{C_{n+2}-C_{n+1}}$, which is equivalent to:

$$
C_{n+1} a^{2}-M_{n+1}>C_{n+2} a^{2}-M_{n+2}
$$

Therefore, $C_{n} a^{2}-M_{n}>C_{n+2} a^{2}-M_{n+2}$ also holds, and worker thus prefers job $n$ to $n+2$.

By similar induction, it is straightforward to show worker prefers job $n$ to any job $k>$ n+1. Q.E.D. 


\section{C.5 Lemma 5}

Proof: The previous arguments imply that workers of ability $a^{2}<\frac{M_{2}-M_{1}}{C 2-C_{1}}$ gains more utilies from performance-pay position at job 1 than job 2. Therefore, the two remaining options for the worker is either fixed-pay position or performance-pay position at job 1 .

When $C_{1} \underline{a}^{2}-M_{1}<\underline{U}$, the employment level at fixed-pay position is positive since those least-abled ones gain higher utility from fixed-pay position. In addition, when

$$
C_{1}\left(a_{2}^{*}\right)^{2}-M_{1}>\underline{U}
$$

performance-pay position at job 1 is also non-empty. Q.E.D.

\section{C.6 Proposition 1}

Proof: It is a direct consequence of Lemma 2-5. Q.E.D.

\section{C.7 Proposition 2}

Proof: Differentiating the expression of $V_{n}$ in equation(11) with respect to $n_{p}$, we have:

$$
\frac{\partial V_{n}}{\partial n_{p}}=V_{n p}+\left(1-2 n_{p}\right)\left(\ln E_{n p}-\ln E_{n F}\right)^{2}>0 \text { if } n_{p}<\frac{1}{2} . \quad \text { Q.E.D. }
$$

\section{C.8 Proposition 3}

\section{Proof:}

(i) Within performance-pay position, the mean of log wage is in turn the weighted average of wages of matched( $\left.\ln E_{n p s}\right)$ and un-matched workers $\left(\ln E_{n p m}\right)$ :

$$
\ln E_{n p}=p_{n} \ln E_{n p s}+\left(1-p_{n}\right) \ln E_{n p m}
$$

Differentiating above with respect to $p_{n}$ gives:

$$
\frac{\partial \ln E_{n p}}{\partial p_{n}}=\ln E_{n p s}-\ln E_{n p m}>0 .
$$


(ii) the inequality within performance-pay position can be decomposed into inequality within matched $\left(V_{n p s}\right)$, unmatched $\left(V_{n p m}\right)$ workers and inequality between them $\left(\ln E_{n p s}-\right.$ $\left.\ln E_{n p m}\right)$ :

$$
V_{n p}=p_{n} V_{n p s}+\left(1-p_{n}\right) V_{n p m}+p_{n}\left(1-p_{n}\right)\left(\ln E_{n p s}-\ln E_{n p m}\right)^{2}
$$

Differentiating the expression above with respect to $p_{n}$, we have:

$$
\frac{\partial V_{n p}}{\partial p_{n}}=\left(V_{n p s}-V_{n p m}\right)+\left(1-2 p_{n}\right)\left(\ln E_{n p s}-\ln E_{n p m}\right)^{2} .
$$

In the following, we compare $V_{n p s}-V_{n p m}$ with $\left(\ln E_{n p s}-\ln E_{n p m}\right)^{2}$

$$
\begin{aligned}
V_{n p s} & =\operatorname{var}_{n}\left(\ln \left[\frac{\left(\mu\left(1-\tilde{\alpha}_{n}\right) \tilde{A}_{n} A_{n} a s\right)^{2}}{b}\right]\right) \\
& =\operatorname{var}_{n}[2 \ln (a s)]=4 \operatorname{var}_{n}[\ln (a s)] \\
V_{n p m} & =\operatorname{var}_{n}\left(\ln \left[\frac{\left(\mu\left(1-\tilde{\alpha}_{n}\right) \tilde{A}_{n} A_{n} a\right)^{2}}{b}\right]\right) \\
& =\operatorname{var}_{n}[2 \ln (a)]=4 \operatorname{var}_{n}[\ln (a)]
\end{aligned}
$$

so

$$
V_{n p s}-V_{n p m}=4 \operatorname{var}_{n}(\ln (s))=4\left\{E\left[(\ln s)^{2}\right]-E[\ln s]^{2}\right\}
$$

In addition

$$
\begin{aligned}
\ln E_{n p s}-\ln E_{n p m} & =\frac{1}{N_{n p}} \int_{a_{n}^{*}}^{a_{n+1}^{*}} \int_{s} \ln s^{2} d G(s) G(a) \\
& =\frac{2}{N_{n p}} \int_{a_{n}^{*}}^{a_{n+1}^{*}} \int_{s} \ln s d G(s) G(a) \\
& =2 \int_{s} \ln s d G(s)=2 E[\ln s]
\end{aligned}
$$


We compute $E[\ln s]$ in the following:

$$
\begin{aligned}
E[\ln s] & =\int_{s} \ln s \frac{\theta_{s}}{s^{\theta_{s}+1}} d s \\
& =-\left.\ln s * s^{-\theta_{s}}\right|_{1} ^{\infty}+\int_{1}^{\infty} s^{-\theta_{s}-1} d s \\
& =\int_{1}^{\infty} s^{-\theta_{s}-1} d s=\frac{1}{\theta_{s}}
\end{aligned}
$$

In addition,

$$
\begin{aligned}
E\left[(\ln s)^{2}\right] & =\int_{s}(\ln s)^{2} \frac{\theta_{s}}{s^{\theta_{s}+1}} d s \\
& =-\left.(\ln s)^{2} * s^{-\theta_{s}}\right|_{1} ^{\infty}+2 \int_{1}^{\infty} \ln s * s^{-\theta_{s}-1} d s \\
& =2\left[-\left.\ln s * \frac{s^{-\theta_{s}}}{\theta_{s}}\right|_{1} ^{\infty}-\int_{1}^{\infty} \frac{s^{-\theta_{s}-1}}{\theta_{s}} d s\right] \\
& =2 \int_{1}^{\infty} \frac{s^{-\theta_{s}-1}}{\theta_{s}} d s=\frac{2}{\theta_{s}^{2}}
\end{aligned}
$$

SO

$$
\begin{aligned}
V_{n p s}-V_{n p m} & =4\left\{E\left[(\ln s)^{2}\right]-E[\ln s]^{2}\right\} \\
& =4\left(\frac{2}{\theta_{s}^{2}}-\frac{1}{\theta_{s}^{2}}\right)=\frac{4}{\theta_{s}^{2}}
\end{aligned}
$$

and

$$
\left(\ln E_{n p s}-\ln E_{n p m}\right)^{2}=\frac{4}{\theta_{s}^{2}}
$$

so it is straightforward to have:

$$
\begin{aligned}
& \left(V_{n p s}-V_{n p m}\right)+\left(1-2 p_{n}\right)\left(\ln E_{n p s}-\ln E_{n p m}\right)^{2} \\
= & \frac{4}{\theta_{s}^{2}}\left(2-2 p_{n}\right)>0 \text { when } p_{n}<1 .
\end{aligned}
$$

These establish the proof. Q.E.D 


\section{Math details on solving model}

Given the definition of $\chi_{j}$ :

$$
\chi_{j}=\left[\frac{\left(\frac{w}{\alpha_{j} A_{j}}\right)^{\frac{\gamma}{1-\gamma}}-\alpha_{j}}{1-\alpha_{j}}\right]^{-\frac{1}{\gamma}}
$$

we can then solve $\frac{w}{A_{j}}$ as

$$
\frac{w}{A_{j}}=\alpha_{j}^{\frac{1}{\gamma}}\left[\frac{\alpha_{j} \chi_{j}^{\gamma}+\left(1-\alpha_{j}\right)}{\alpha_{j} \chi_{j}^{\gamma}}\right]^{\frac{1-\gamma}{\gamma}} .
$$

Hence, the total wage payment to fixed-pay position $\frac{w \chi_{j} H_{j P}}{A_{j}}$ can be written as:

$$
\begin{aligned}
\tilde{E}_{j F} & =\alpha_{j}^{\frac{1}{\gamma}}\left[\frac{\alpha_{j} \chi_{j}^{\gamma}+\left(1-\alpha_{j}\right)}{\alpha_{j} \chi_{j}^{\gamma}}\right]^{\frac{1-\gamma}{\gamma}} \chi_{j} H_{j P} \\
& =\left[\alpha_{j} \chi_{j}^{\gamma}+\left(1-\alpha_{j}\right)\right]^{\frac{1}{\gamma}}\left[\frac{\alpha_{j} \chi_{j}^{\gamma}}{\alpha_{j} \chi_{j}^{\gamma}+\left(1-\alpha_{j}\right)}\right] H_{j P} \\
& =\tilde{A}_{j} \tilde{\alpha}_{j} H_{j P},
\end{aligned}
$$

where $\tilde{\alpha}_{j}=\frac{\alpha_{j} \chi_{j}^{\gamma}}{\alpha_{j} \chi_{j}^{\gamma}+\left(1-\alpha_{j}\right)}$. The total payment to performance-pay position is thus $\tilde{E}_{j P}=$ $\mu\left(1-\tilde{\alpha}_{j}\right) \tilde{A}_{j} H_{j P}$.

The representative firm decides the employment level at fixed-pay position to maximize the profit net of payment to workers at fixed-pay position. That is,

$$
\max _{N_{j F}}\left[\alpha_{j} A_{j} H_{j F}^{\gamma}+\left(1-\alpha_{j}\right) H_{j p}^{\gamma}\right]^{\frac{1}{\gamma}}-w N_{j F}
$$

Solving the maximization problem above, the following relation can be established: $H_{j F}=\chi_{j} H_{j P}$. Substitute it into the production function, we have:

$$
Y_{j}=\left[\alpha_{j}\left(\chi_{j} H_{j P}\right)^{\gamma}+\left(1-\alpha_{j}\right) H_{j p}^{\gamma}\right]^{\frac{1}{\gamma}}=\tilde{A}_{j} H_{j P}
$$

where $\tilde{A}_{j}=\left[\alpha_{j} \chi_{j}^{\gamma}+\left(1-\alpha_{j}\right)\right]^{\frac{1}{\gamma}}$. 